\title{
SOLUÇÕES INTEGRANDO BIM E INTERNET DAS COISAS NO CICLO DE VIDA DA EDIFICAÇÃO: UMA REVISÃO CRÍTICA
}

\section{SOLUTIONS INTEGRATING BIM AND INTERNET OF THINGS IN BUILDING LIFE CYCLE: A CRITICAL REVIEW}

\author{
Fernanda Almeida Machado 1 \\ Universidade Estadual de Campinas, Campinas, SP, Brasil, fernanda.machado@nucleobim.com
}

Regina Coeli Ruschel 2

Universidade Estadual de Campinas, Campinas, SP, Brasil, ruschel@g.unicamp.br

\begin{abstract}
Resumo
O objetivo deste artigo é identificar, analisar e estratificar em classes de problemas os componentes, modelos e métodos das soluções existentes na literatura que integram Modelagem da Informação da Construção (BIM) e Internet das Coisas (IoT). Foram adotados os procedimentos metodológicos da Revisão Sistemática da Literatura (RSL) para o mapeamento de estudos convergentes, a identificação de artefatos já produzidos inerentes à integração mencionada e a configuração de classes de problemas. Os resultados constatam artefatos concentrados majoritariamente na fase de Operação e Manutenção da edificação e interesse crescente na fase de Construção e Comissionamento; maior recorrência de modelos e instanciações na integração de BIM e IoT, que atende a nove classes de problemas distintos e apresenta-se em pleno desenvolvimento. São discriminados as séries e os usos do modelo BIM empregados em cada contexto, bem como as tecnologias utilizadas. Ademais, são evidenciados os propósitos do BIM e da IoT na integração e os principais agentes envolvidos no processo. Apontam-se novos campos de pesquisa em um estágio post-BIM, nos quais a modelagem da informação da construção transcende para um contexto multidisciplinar, abarcando soluções específicas de Tecnologias da Informação e Comunicação (TIC) e Sensoriamento que devem ampliar as relações estáticas ou dinâmicas entre os ambientes físico e virtual.
\end{abstract}

Palavras-chave: BIM. Internet das Coisas. Interface BIM/IoT. Revisão Sistemática da Literatura.

\begin{abstract}
This article aims at identifying, analyzing and classifying in classes of problems the components, models, and methods related to the integration of Building Information Modeling (BIM) and Internet of Things (IoT) from existing studies in literature. The adopted methodology followed the Literature Systematic Review (LSR) guidelines and aimed to map related studies, identify artifacts that enable such integration and configure classes of problems. The results detect artifacts mostly concentrated in the phase of Operation and Maintenance and the increase of interest in the phase of Construction and Commissioning. Furthermore, models and instantiations are recurrent artifacts in BIM/IoT integration, which addresses nine classes of problems and is in full development. BIM model series and uses applied in each context are presented, as well as the technologies associated. Also, the purposes of BIM and IoT in the integration are pointed out as well as the main agents involved. The authors indicate new research fields in a postBIM stage, in which building information modeling transcends for a multidisciplinary context, embracing Sensing Technologies and Information and Communication Technology (ICT) solutions that may expand static or dynamic relations between physical and virtual environments.
\end{abstract}

Keywords: BIM. Internet of Things. BIM/IoT Interfacing. Literature Systematic Review.

\footnotetext{
How to cite this article:

MACHADO, Fernanda Almeida; RUSCHEL, Regina Coeli. Soluções integrando BIM e Internet das Coisas no ciclo de vida da edificação: uma revisão crítica. PARC Pesquisa em Arquitetura e Construção, Campinas, SP, v. 9, n. 3, p. 204-222, set. 2018. ISSN 1980-6809. Disponível em: <https://periodicos.sbu.unicamp.br/ojs/index.php/parc/article/view/8650216>. Acesso em: 23 set. 2018. doi:https://doi.org/10.20396/parc.v9i3.8650216.
} 


\section{Introdução}

A Modelagem da Informação da Construção (BIM) é um paradigma inovador, que consiste em um conjunto interativo de políticas, processos e tecnologias (SUCCAR, 2009) para produzir metodologias de gestão da produção e da informação da edificação por todo o seu ciclo de vida (PENTTILA, 2006). A espinha dorsal desse conjunto é constituída por modelos 3D digitais, semanticamente ricos e habilitados para compartilhar e trocar dados (GSA, 2006; ISIKDAG, 2015). Sua efetivação na indústria da Arquitetura, Engenharia, Construção e Operação (AECO) pode ser mensurada por marcos de desempenho que indicam potencialidades organizacionais de atender a requisitos mínimos relativos a cada estágio de implementação - modelagem baseada em objeto, colaboração baseada em modelo e integração baseada em rede. A superação desses estágios conduz a um cenário variável, em constante evolução, denominado post-BIM. O post-BIM representa objetivos voltados para o emprego de ferramentas e conceitos virtualmente integrados no contexto da edificação (SUCCAR, 2010). Este cenário tende a ser subsidiado por Tecnologias de Informação e Comunicação (TICs), aptas a ampliar as capacidades de gestão das diversas fases do ciclo de vida (UNDERWOOD; ISIKDAG, 2011; SABOL， 2013; ISIKDAG, 2015).

O contexto de evolução do BIM junto às TICs é evidenciado em Succar, Saleeb e Sher (2016), por meio da classificação de usos do modelo associados ao domínio de construção. A Interface BIM/IoT, temática deste estudo, consta em uma das categorias de extensão de usos do modelo. A Internet das Coisas (ou IoT, Internet of Things) é um paradigma que envolve diferentes tecnologias e consiste em uma infraestrutura de rede global de objetos interconectados, que não somente coleta informações do ambiente físico e interage com o mundo real, como também utiliza protocolos de rede existentes para fornecer serviços de transferência, análise, aplicação e comunicação de informações, com ou sem intervenção humana (EUROPEAN COMISSION, 2010; VERMESAN et al., 2011; GUBBI et al., 2013). Essa interconexão pode desdobrar-se na criação de cenários inteligentes em diversos domínios de aplicação, a exemplo de cidades, ambientes, domótica e automação residencial, segurança e emergências, logística, controle industrial, varejo, dentre outros (ASIN; GASCON, 2012).

Considerando os domínios de aplicação inerentes ao ambiente construído, a integração de BIM e IoT pode consistir no uso do modelo BIM como uma interface beneficiada por dados fornecidos através de uma rede de equipamentos, sensores e dispositivos móveis. Os desdobramentos decorrentes dessa integração apontam para: (i) o uso do modelo BIM em tempo real, visando à exibição de dados coletados através de redes de sensores; (ii) o uso do modelo BIM para rastreamento de ativos, visando à localização de ativos fixos ou móveis por meio de tecnologias de rastreamento e marcação; e (iii) o uso do modelo BIM para automação predial, visando o monitoramento e controle da edificação (SUCCAR; SALEEB; SHER, 2016; BIM DICTIONARY, 2017).

Diante dessa perspectiva, que envolve o post-BIM, o presente artigo apresenta uma Revisão Sistemática da Literatura (RSL), cujo objetivo é identificar, analisar e estratificar em classes de problemas os componentes, modelos e métodos das soluções existentes na literatura que integram BIM e IoT.

\section{Interface BIM/loT}

A integração de informações adquiridas por meio da IoT aos objetos ${ }^{1}$ que compõem um modelo BIM torna-se fundamental para proporcionar sua representação, contextualização e correlação com determinada edificação em tempo real (ISIKDAG, 2015). Underwood e Isikdag (2011) e Isikdag (2015) sugerem uma nova caracterização, a qual o modelo BIM evolui para um modelo integrado de informação distribuída - sempre atualizado e aberto para inserção de novas informações. Sabol (2013) destaca que as potencialidades propiciadas pelas TICs devem posicionar o modelo BIM como um portal visual 3D, habilitado a oferecer acesso tanto a informações estáticas (ex. data de instalação) como dinâmicas (ex. estado atual) de objetos da edificação - fornecendo feedbacks mais intuitivos de análise.

Essas transformações iminentes do modelo BIM demandam novas capacidades que devem ser incorporadas fazendo-se uso de tecnologias facilitadoras, como: Redes de Sensores Sem Fio (RSSF), Computação em Nuvem, Serviços Web e Web Semântica (UNDERWOOD; ISIKDAG, 2011), Tecnologia de Identificação por Radiofrequência (RFID) e Realidade Aumentada (RA) (SABOL, 2013).

A RSSF possui a capacidade de coletar e produzir grandes montantes de dados. Seu uso pode contribuir para a atribuição de informações do ambiente físico diretamente na geometria da edificação, por meio das propriedades de objetos do modelo BIM (SABOL, 2013; SUCCAR; SALEEB; SHER, 2016). De modo semelhante, podem-se afiliar identificadores inerentes à Tecnologia RFID nos objetos BIM, para mediar atividades associadas com a gestão de ativos (SABOL, 2013). Reitera-se que a Tecnologia RFID faz uso de leitores e marcadores para monitorar objetos em tempo real, através de processamento remoto (PERERA et al., 2013). Em ambos os casos, sinaliza-se a demanda pelo aprimoramento de métodos de visualização, análise e avaliação de informações (SABOL, 2013). 
A Computação em Nuvem é uma tecnologia que envolve a virtualização de ambientes de ampla capacidade de armazenamento. Seu uso deve proporcionar ao modelo BIM residir em um repositório de dados disponível e acessível via web (UNDERWOOD; ISIKDAG, 2011; ISIKDAG, 2015). Ademais, há a possibilidade de esta tecnologia dar suporte a análises intensivas, através da recepção de dados em tempo real e de seu potencial em integrar-se à computação móvel (SABOL, 2013). Ainda no contexto $w e b$, as Arquiteturas Orientadas a Serviços (SOA) e os Serviços Web oferecem oportunidades de gerar combinações e relações entre dados, e tornar a informação da edificação dinâmica - em tempo real, precisa e atualizada. Agregada a este cenário, a Web Semântica ${ }^{2}$ pode proporcionar que consultas sobre as novas informações possam ser respondidas, caso estejam subsidiadas por ontologias e em conformidade com padrões semânticos da web (UNDERWOOD; ISIKDAG, 2011; ISIKDAG, 2015). Por fim, a RA associada ao modelo BIM pode propiciar diversas experiências ampliadas ao usuário, através da sobreposição de dados virtuais com o ambiente real (WANG et al., 2012). As aplicações podem viabilizar a exibição de informações de consumo projetadas na edificação, listas de registros de ativos, informações relativas a infraestrutura, dentre outras atividades características de Operação e Manutenção (O\&M) da edificação (SABOL, 2013).

Essas tecnologias facilitadoras que podem integrar-se ao modelo BIM, distribuem-se nas quatro camadas que estruturam a IoT e sua Arquitetura Orientada a Serviço: sensoriamento, rede, serviço e interface (Figura 1) (LI; $\mathrm{XU}$; ZHAO, 2014). A camada de sensoriamento é formada por componentes de hardware e software, que são capazes de capturar automaticamente o ambiente e trocar dados entre dispositivos. As funções desta camada abarcam detecção, atuação, identificação, interação e comunicação. A camada de rede consiste em uma infraestrutura que conecta todos os objetos e os torna sensíveis ao ambiente. Através dessa infraestrutura, há compartilhamento, gestão e processamento de dados. A camada de serviço é baseada na tecnologia middleware e contempla tanto os armazenamentos sob demanda de usuários e aplicações, como as ferramentas computacionais para análise de dados. Por sua vez, a camada de interface consiste em métodos de interação com usuários e aplicações, e envolve ferramentas de visualização e interpretação (GUBBI et al., 2013; LI; XU; ZHAO, 2014).

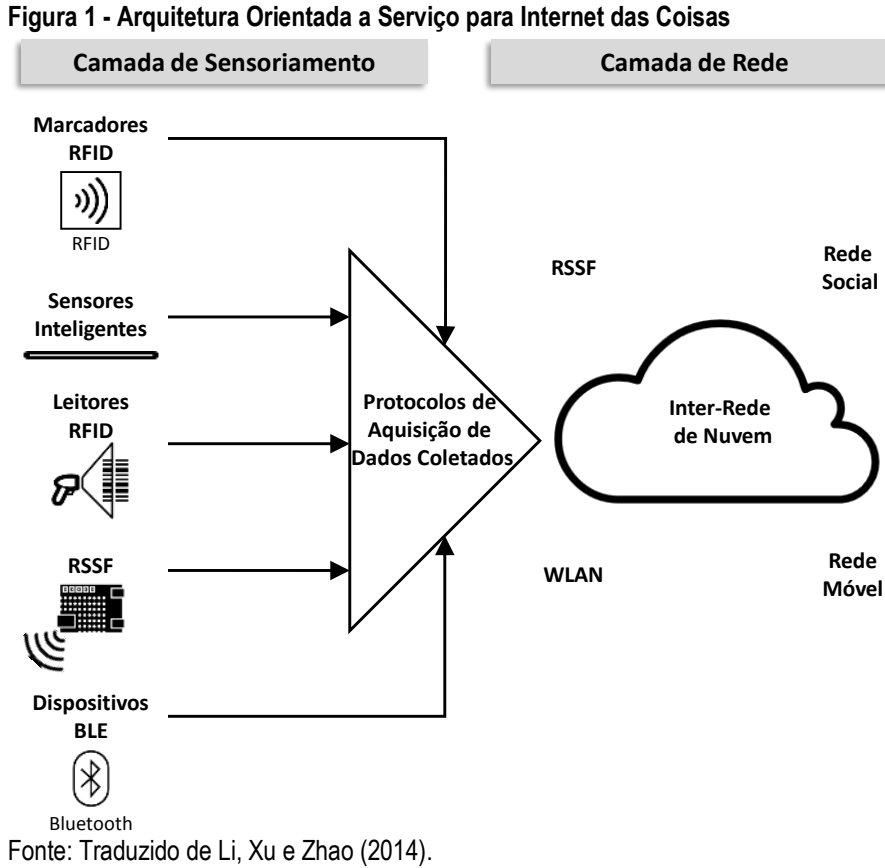

\section{Revisão Sistemática da Literatura}

A Revisão Sistemática da Literatura (RSL) é um mecanismo para identificar, avaliar e interpretar toda pesquisa relevante e disponível relativa a uma determinada questão, tópico ou fenômeno de interesse específico. Seus desdobramentos permitem uma visão robusta da área de estudo em análise (DRESCH; LACERDA; ANTUNES JÚNIOR, 2015).
A revisão apresentada adotou o delineamento de Kitchenham (2004). Seus procedimentos metodológicos, detalhados a seguir, consistem: (i) no Planejamento da Revisão, o qual é concebido o Protocolo e os Formulários de Condução de Busca; (ii) a Condução da Revisão, a qual envolve a aplicação de critérios de inclusão/exclusão dos estudos primários mapeados, bem como o preenchimento de Formulários de Extração de Dados; e (iii) a Análise dos 
Resultados, dedicada à sumarização e explanação dos resultados obtidos.

\section{Planejamento da Revisão}

O mapeamento dos estudos primários foi estruturado através do protocolo de busca, discriminando objetivo, questões de pesquisa, estratégias de busca, bases de dados contempladas, critérios de inclusão e exclusão empregados, estratégias de extração de dados, e sumarização dos resultados.

Definiu-se o objetivo da RSL em identificar, analisar e estratificar em classes de problemas os componentes, modelos e métodos das soluções existentes na literatura que integram BIM e IoT. Entende-se componentes, modelos, métodos e soluções como artefatos, de acordo com a classificação de March e Smith (1995). Os componentes, denominados constructos, constituem uma conceituação utilizada para descrever os problemas dentro de um domínio e especificar suas respectivas soluções, de modo que sejam definidos os termos empregados na descrição e na concepção das tarefas. Os modelos são um conjunto de proposições ou declarações que expressam as relações entre os constructos, visualizados como uma descrição ou representação de uma configuração ou estrutura real. Os métodos são um conjunto de passos utilizados para executar tarefas, e baseiam-se nos constructos e modelos elaborados para determinada solução. Finalmente, as instanciações representam a solução concretizada, no sentido de produzir resultados em um determinado contexto. Elas agregam a operacionalização dos demais artefatos, demonstrando sua viabilidade e eficácia.

As questões de pesquisa abarcaram: quais são os artefatos desenvolvidos com ênfase na integração de BIM e IoT; em que fases do ciclo de vida da edificação há maior recorrência destes artefatos; quais são os usos do modelo BIM utilizados para viabilizar estes artefatos; e que TICs são empregadas nesta integração.

Como estratégias de busca, definiu-se que as fontes deveriam estar publicadas em periódicos científicos revisados por pares, disponíveis integralmente em meio eletrônico, no idioma inglês e no intervalo temporal 20002016. Esse intervalo temporal abarca estudos publicados após o primeiro emprego do termo Internet of Things por Kevin Ashton em 1999 (ASHTON, 2009) e da publicação do livro Building Product Models: Computer Environments, Supporting Design and Construction por Eastman (1999), até os dias atuais. Os termos de busca utilizados foram "Internet of Things", "IoT", "Building Information Model*", "BIM", "Real-time Data" e "Sensor"; "Radio-Frequency" e RFID; Bluetooth e BLE; "Near Field Communication" e NFC; "Ultra Wide Band" e UWB; sendo realizadas todas as combinações possíveis entre "Building Information Model" "ou BIM e os demais.

As buscas foram efetuadas nas bases de dados SCOPUS, Compendex, ASCE Library e Web of Science. Para dar suporte à seleção de estudos relevantes que atendam às questões de pesquisa, foram elaborados critérios de inclusão e exclusão dos estudos primários. Como critérios de inclusão adotaram-se: (a) Trabalhos que abordam a integração de BIM e IoT em qualquer fase do ciclo de vida da edificação; e (b) Trabalhos que possuem os termos de busca ao menos no título, resumo ou palavras-chave. Como critérios de exclusão adotaram-se: (a) Trabalhos repetidos; (b) Trabalhos não direcionados para a área da AECO e (c) Trabalhos que não abordam a camada de sensoriamento da IoT na integração, por não assegurarem a interação com o ambiente físico.

As estratégias de extração de dados sobre os estudos selecionados para a leitura analítica integral subsidiaram o preenchimento de um conjunto de formulários específicos, considerando os seguintes aspectos de identificação e classificação: (i) tipos de artefato, de acordo com March e Smith (1995); (ii) séries (que representam conjuntos de usos) e usos do modelo BIM para o domínio de construção, ambos fundamentados na taxonomia elaborada por Succar, Saleeb e Sher (2016) ${ }^{3}$; (iii) soluções de tecnologia BIM (software, hardware e network), conforme Succar (2009); e (iv) soluções de tecnologia IoT, baseado em Li, Xu e Zhao (2014). A definição das classes de problemas está relacionada aos tópicos abordados por cada estudo. $\mathrm{O}$ momento de sumarização dos resultados auxiliou no apontamento de padrões e correlações entre os estudos levantados.

\section{Condução da Revisão}

O Quadro 1 apresenta o histórico de ações de extração das fontes e aplicações de filtros de inclusão e exclusão dos estudos, como estabelecido no planejamento da RSL. Assim, a amostra para análise abrange o total de quarenta e cinco publicações em periódicos.

\section{Análise dos Resultados}

Inicialmente, as publicações da amostra foram agrupadas por fases do ciclo de vida da edificação baseadas em NIST (2006): Planejamento/Programa e Projeto; Construção e Comissionamento; Operação e Manutenção; e Demolição ou Descarte. Ademais, foi aplicado um agrupamento para os casos de publicações atemporais. Ressalta-se que os estudos continuados de um mesmo grupo de autores foram analisados em conjunto.

Seguindo os critérios estabelecidos no presente artigo, observa-se que as abordagens sobre a integração de BIM e IoT começaram a ser publicadas em periódicos a partir de 2008 (Figura 2). Constata-se que a integração tem maior 
destaque na fase de Operação e Manutenção da edificação entre 2013 e 2015. Por outro lado, há interesse crescente na integração em Construção e Comissionamento, tendo em vista o predomínio de publicações nesta fase em 2016. Por sua vez, o levantamento geral de artefatos aponta os tipos "modelo" e "instanciação" como as criações mais recorrentes nesse âmbito, considerando todas as fases do ciclo de vida da edificação (Figura 3). Esse cenário sinaliza maior desenvolvimento científico em estruturas de relacionamento precisas (modelo) e, consequentemente, a necessidade de provas de conceito e testes de aplicação de protótipos (instanciação).

\begin{tabular}{|c|c|c|c|c|}
\hline Parâmetros & \multicolumn{4}{|c|}{ Aplicações da Busca } \\
\hline Bases de Dados & COMPENDEX & ASCE LIBRARY & WEB OF SCIENCE & SCOPUS \\
\hline Campo de Busca & Subject/Title/Abstract & Anywhere & Topic & Title/Abstract/Keywords \\
\hline Tipo de Publicação & Journal Article & $\mathrm{N} / \mathrm{A}$ & Article & Article \\
\hline Resultado & 77 & 7 & 79 & 107 \\
\hline Eliminação por repetição na mesma base & 35 & 2 & 32 & 52 \\
\hline Total de publicações por base & 42 & 5 & 47 & 55 \\
\hline Total de publicações & \multicolumn{4}{|c|}{149 publicações } \\
\hline Eliminação por repetição entre bases & \multicolumn{4}{|c|}{87 publicações } \\
\hline Publicações resultantes & \multicolumn{4}{|c|}{62 publicações } \\
\hline Eliminação por critérios de exclusão & \multicolumn{4}{|c|}{17 publicações } \\
\hline Total da Amostra & \multicolumn{4}{|c|}{45 publicações } \\
\hline
\end{tabular}

Fonte: As autoras.

Figura 2 - Percentual e número de publicações por ano e fase do ciclo de vida

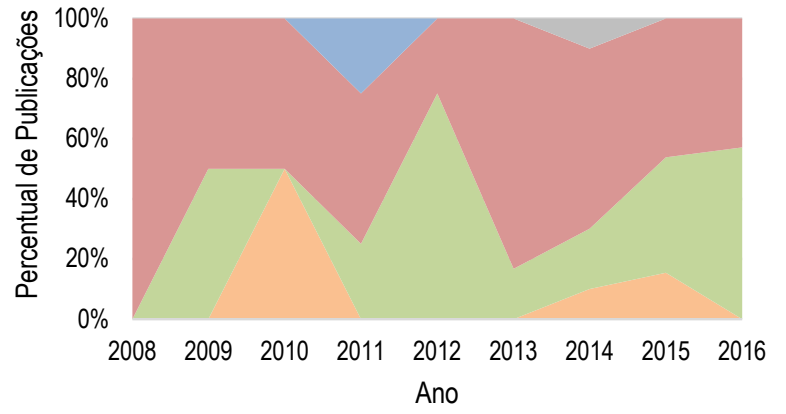

Planejamento/Programa e Projeto Construção e Comissionamento

Fonte: As autoras

Figura 3 - Radar de artefatos no contexto da integração de BIM e loT

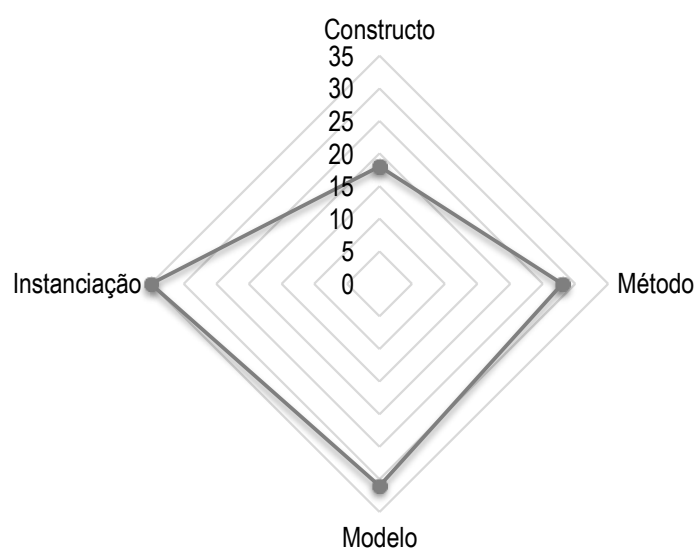

Fonte: As autoras.

\section{BIM e loT no Planejamento/Programa e Projeto}

O agrupamento de estudos inerentes a Planejamento/Programa e Projeto (Quadro 2) abrange quatro publicações e a integração de BIM e IoT atende a três classes de problemas: Sensibilidade à Eficiência Energética, Planejamento de Sistemas Inteligentes e

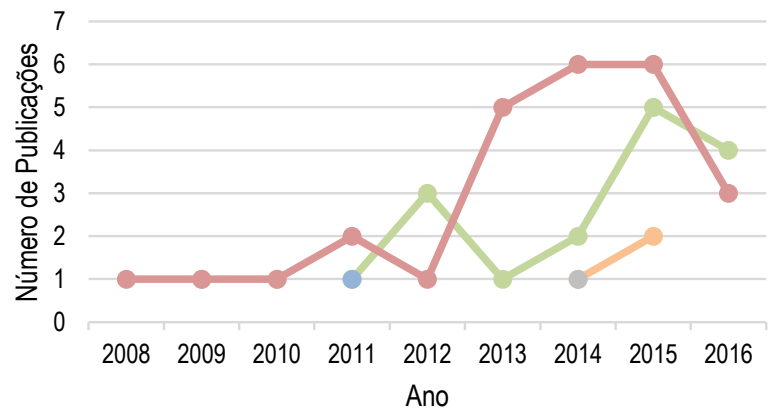

- Operação e Manutenção $\square$ Demolição ou Descarte $\square$ Atemporal

Concepção e Autoria de Projetos. A síntese de Séries e Usos do Modelo identificados nesta fase é apresentada na Figura 4, e envolve cinco séries distintas associadas a dezessete usos do modelo. Destaca-se a aplicação do modelo em Autoria de Projeto, associado a uma gama de usos da série de Simulação e Quantificação. O uso da Interface BIM/IoT contribui em etapas iniciais de projeto e cenários de retrofit, relacionando-se com a série de Monitoramento e Controle.

A classe de problemas relativa a Sensibilidade à Eficiência Energética é abordada por Crosbie, Dawood e Dean (2010). Os autores elaboram um método de produção e uso de modelos BIM para identificar estratégias de projeto e/ou operação, baseadas em desempenho. As aplicações potenciais do estudo contemplam uma mesma edificação em todo o seu ciclo de vida e cenários de retrofit, já que ambos viabilizam a comparação entre perfis preditivos (simulação) e reais (monitoramento) de energia da edificação para tomadas de decisão (controle) e otimização do consumo. 
Figura 4 - Síntese de Séries e Usos do Modelo: estudos da fase de Planejamento/Programa e Projeto

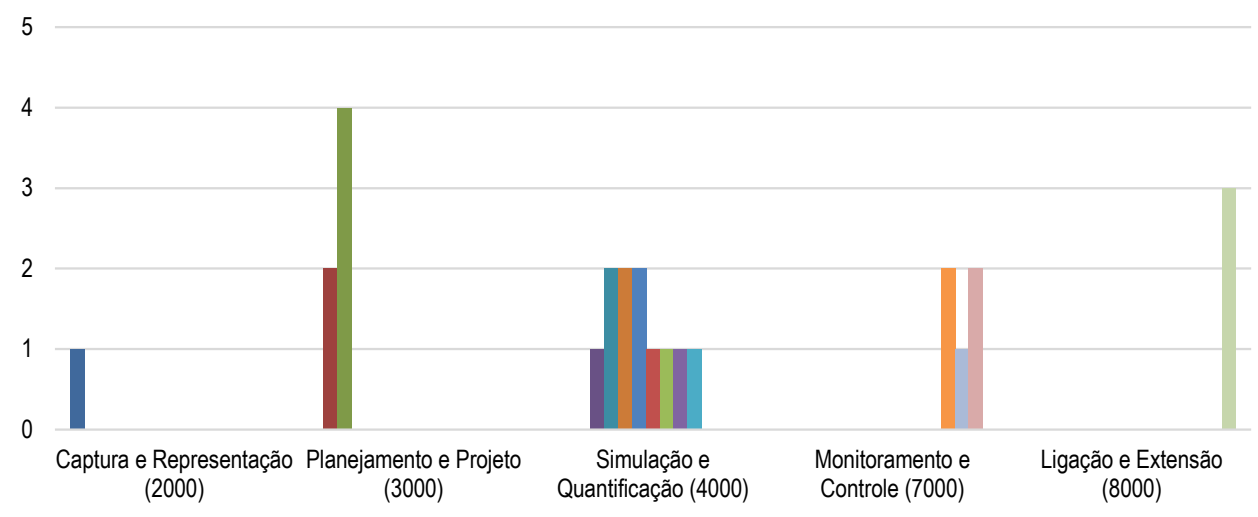

- Manutenção de Registros (2070)

- Concepção (3010)

Autoria de Projeto (3040)

Estimativa de Custo (4070)

- Consumo de Energia (4090)

- Análise de lluminação (4120)

- Análise Solar (4190)

- Análise Espacial (4200)

- Análise de Sustentabilidade (4220)

- Análise Térmica (4230)

- Avaliação do Ciclo de Vida (4250)

- Automação Predial (7010)

Monitoramento de Desempenho (7030)

- Utilização em Tempo Real (7040)

Interface BIM/loT (8050)

Fonte: As autoras.

Quadro 2 - Integração de BIM e loT: Planejamento/Programa e Projeto

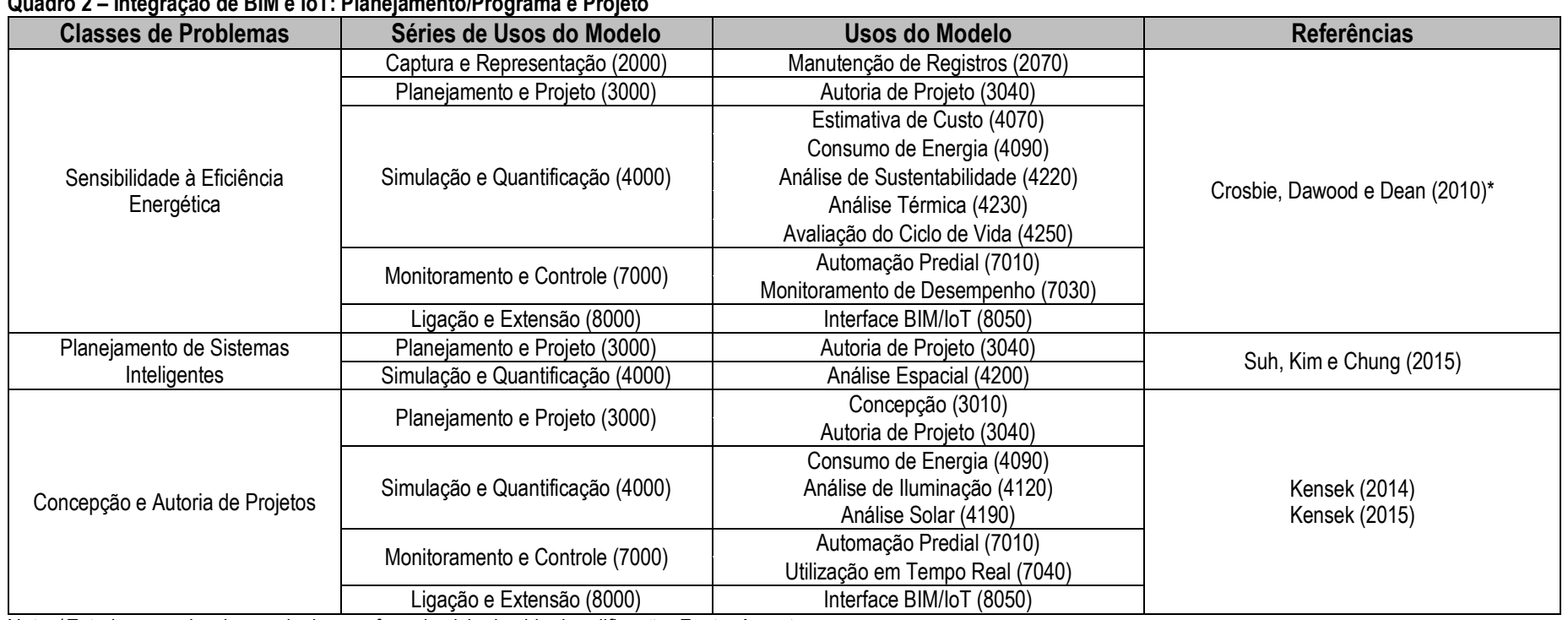

Nota: *Estudos que abordam mais de uma fase do ciclo de vida da edificação. Fonte: As autoras.

A classe de problemas relativa a Planejamento de Sistemas Inteligentes é abordada por Suh, Kim e Chung (2015). Os autores apresentam diretrizes de elaboração de sistemas de sensores baseados em rede para habitações inteligentes de idosos. As diretrizes contemplam a integração colaborativa de projetos arquitetônicos e de sistemas de TI utilizando o modelo BIM (ex. inclusão de bibliotecas de objetos de redes de sensores para modularização e convergência de tecnologias). O estudo visa contribuir para reduzir interferências espaciais e ampliar a eficácia de monitoramento e controle aplicado a saúde, segurança, conveniência e consumo dos idosos.

A classe de problemas relativa à Concepção e Autoria de Projetos é abordada em Kensek (2014, 2015), que explora o conceito de sistemas inteligentes em projetos de edifícios sustentáveis. A autora apresenta soluções bidirecionais, e em tempo real, de interação entre protótipos físicos e modelos BIM, utilizando sensores e atuadores mediados por placas de microcontrolador. As interações foram viabilizadas através do uso de ambientes de Linguagem de
Programação Visual (VPL) (ex. Grasshopper e Dynamo) e de linguagem nativa para a plataforma .NET, que podem atuar como middleware mediante acesso à Interface de Programação de Aplicativos (API) da ferramenta BIM de autoria (Autodesk Revit). As aplicações almejam considerar, desde as etapas iniciais de projeto, o comportamento interativo de componentes de fachada (brises, painéis e aberturas) em relação à intensidade de iluminação incidente.

\section{BIM e loT na Construção e Comissionamento}

O agrupamento de estudos inerentes a Construção e Comissionamento (Quadro 3) abrange dezessete publicações e a integração de BIM e IoT atende a três classes de problemas: Gestão de Saúde e Segurança no Ambiente de Trabalho, Deteç̧ão e Rastreamento de Objetos Inteligentes, e Visualização, Interação e Comunicação entre Agentes no Ambiente de Trabalho. A síntese de Séries e Usos do Modelo identificados nesta fase é apresentada na Figura 5 e Figura 6, e envolve sete séries distintas associadas a vinte e seis usos aplicados ao 
modelo. Observa-se ênfase desta fase nas seguintes séries: Construção e Fabricação, associada ao uso na Logística de Construção; Operação e Manutenção, aplicada no Rastreamento de Ativos; e Monitoramento e Controle, referente à Utilização em Tempo Real e em Campo. Essas aplicações apresentaram recorrência no canteiro de obras e em ambientes de trabalho associados. Ainda, os usos destacados estão correlacionados à série de Ligação e Extensão, por meio do emprego da Interface BIM/IoT e da Extensão em Serviços Web.

Figura 5 -- Síntese de Séries e Usos do Modelo: estudos da fase de Construção e Comissionamento (Parte 1)

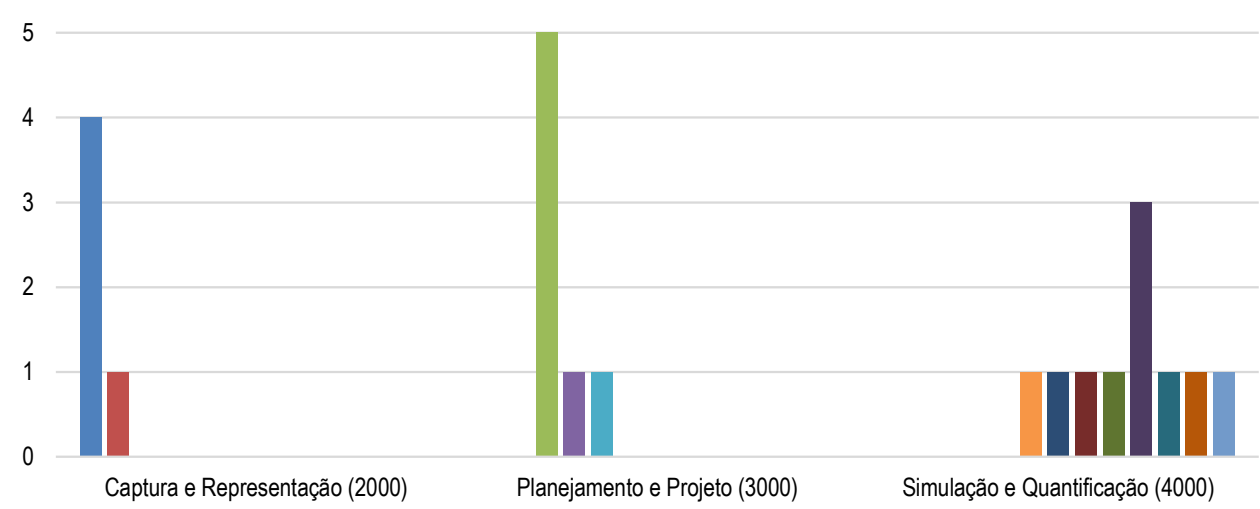

Fonte: As autoras.

Figura 6 - Síntese de Séries e Usos do Modelo: estudos da fase de Construção e Comissionamento (Parte 2 )

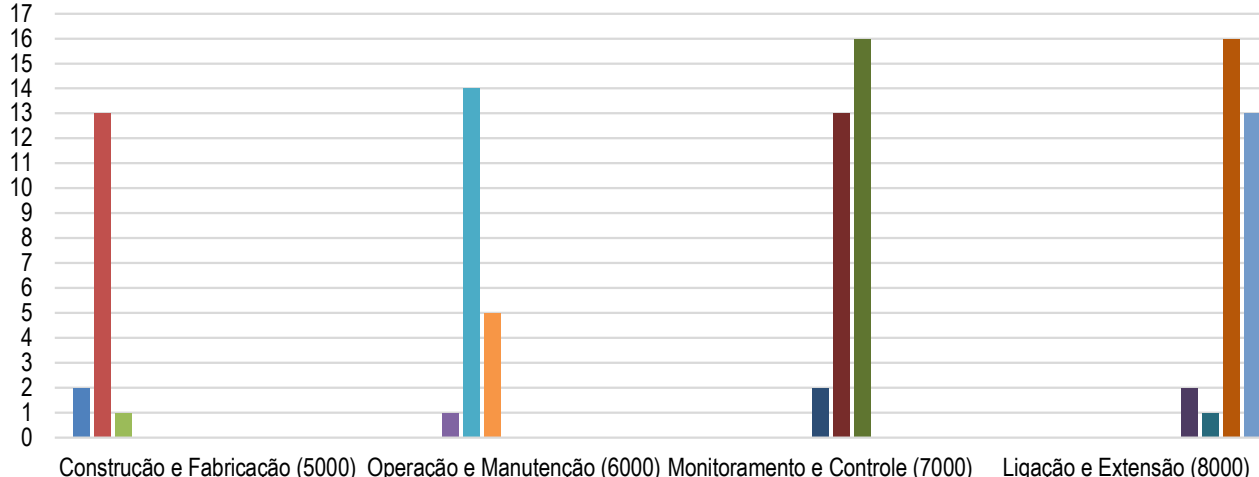

Construção e Fabricação (5000) Operação e Manutenção (6000) Monitoramento e Controle (7000) Ligação e Extensão (8000)

\author{
- Representação As-Constructed (2030) \\ - Comunicação Visual (2090) \\ - Planejamento da Construção (3020) \\ - Análise do Processo Lean (3060) \\ a Planejamento de Içamento (3070) \\ - Simulação em RA (4030) \\ - Detecção de Interferências (4040) \\ - Estimativa de Custo (4070) \\ - Egresso e Ingresso (4080) \\ - Avaliação de Risco e Perigo (4150) \\ - Análise de Segurança (4160) \\ - Análise Espacial (4200) \\ - Simulação em Realidade Virtual (4240)
}

Fonte: As autoras.

- Pré-Moldagem de Concreto (5040)

- Logística de Construção (5050)

- Modelagem de Chapa Metálica (5070)

- Manutenção de Ativos (6010)

- Rastreamento de Ativos (6030)

- Inspeção Predial (6040)

- Automação Predial (7010)

- BIM em Campo (7020)

- Utilização em Tempo Real (7040)

- Ligação BIM/ERP (8020)

- Integração BIM/FM (8030)

- Interface BIM/loT (8050)

- Extensão em Serviços Web (8070)

Quadro 3 - Integração de BIM e loT: Construção e Comissionamento

\begin{tabular}{|c|c|c|c|}
\hline Classes de Problemas & Séries de Ulsos do Modelo & llsos do Modeln & Referência \\
\hline \multirow{6}{*}{$\begin{array}{c}\text { Gestão de Saúde e Segurança no } \\
\text { Ambiente de Trabalho }\end{array}$} & Planejamento e Projeto $(3000)$ & Planejamento da Construção (3020) & \multirow{6}{*}{$\begin{array}{c}\text { Arslan et al. (2014) } \\
\text { Riaz et al. (2014) } \\
\text { Costin, Teizer e Schoner (2015) } \\
\text { Fang et al. (2016) } \\
\text { Park, Kim e Cho (2016) }\end{array}$} \\
\hline & Simulação e Quantificação (4000) & $\begin{array}{l}\text { Egresso e Ingresso (4080) } \\
\text { Avaliação de Risco e Perigo (4150) } \\
\text { Análise de Segurança (4160) } \\
\text { Análise Espacial (4200) }\end{array}$ & \\
\hline & Construção e Fabricação (5000) & Logística de Construção (5050) & \\
\hline & Operação e Manutenção (6000) & $\begin{array}{l}\text { Rastreamento de Ativos (6030) } \\
\text { Inspeção Predial (6040) }\end{array}$ & \\
\hline & Monitoramento e Controle (7000) & $\begin{array}{c}\text { Automação Predial (7010) } \\
\text { BIM em Campo (7020) } \\
\text { Utilização em Tempo Real (7040) }\end{array}$ & \\
\hline & Ligação e Extensão (8000) & $\begin{array}{c}\text { Interface BIM/loT (8050) } \\
\text { Extensão em Serviços Web (8070) }\end{array}$ & \\
\hline
\end{tabular}




\begin{tabular}{|c|c|c|c|}
\hline Classes de Problemas & Séries de Usos do Modelo & Usos do Modelo & Referência \\
\hline \multirow{6}{*}{$\begin{array}{l}\text { Detecção e Rastreamento de } \\
\text { Objetos Inteligentes }\end{array}$} & Captura e Representacão (2000) & Representacão As-Constructed (2030) & \multirow{6}{*}{$\begin{array}{c}\text { Akanmu, Anumba e Messner (2012)* } \\
\text { Niu et al. }(2015)^{\star}\end{array}$} \\
\hline & Planejamento e Projeto (3000) & Planejamento da Construção (3020) & \\
\hline & Construção e Fabricação (5000) & $\begin{array}{l}\text { Pré-Moldagem de Concreto (5040) } \\
\text { Logística de Construção (5050) }\end{array}$ & \\
\hline & Operação e Manutenção (6000) & $\begin{array}{l}\text { Manutenção de Ativos (6010) } \\
\text { Rastreamento de Ativos (6030) } \\
\text { Inspeção Predial (6040) }\end{array}$ & \\
\hline & Monitoramento e Controle (7000) & $\begin{array}{c}\text { BIM em Campo (7020) } \\
\text { Utilização em Tempo Real (7040) }\end{array}$ & \\
\hline & Ligação e Extensão (8000) & $\begin{array}{c}\text { Integração BIM/FM (8030) } \\
\text { Interface BIM/loT (8050) } \\
\text { Extensão em Serviços Web (8070) }\end{array}$ & \\
\hline \multirow{7}{*}{$\begin{array}{l}\text { Visualização, Interação e } \\
\text { Comunicação entre Agentes no } \\
\text { Ambiente de Trabalho }\end{array}$} & Captura e Representação (2000) & $\begin{array}{l}\text { Representação As-Constructed (2030) } \\
\text { Comunicação Visual (2090) }\end{array}$ & \multirow{7}{*}{$\begin{array}{l}\text { Motamedi e Hammad (2009)* } \\
\text { Xie, Shi e Issa (2011) } \\
\text { Lee et al. (2012) } \\
\text { Wang et al. (2012) } \\
\text { Ikonen et al. (2013) } \\
\text { Feng et al. (2015) } \\
\text { Akanmu et al. (2015) } \\
\text { Dave et al. (2015) } \\
\text { Li et al. (2016a) } \\
\text { Li et al. (2016b) }\end{array}$} \\
\hline & Planejamento e Projeto (3000) & $\begin{array}{l}\text { Planejamento da Construção (3020) } \\
\text { Análise do Processo Lean (3060) } \\
\text { Planejamento de Içamento (3070) }\end{array}$ & \\
\hline & Simulação e Quantificação (4000) & $\begin{array}{c}\text { Simulação em RA (4030) } \\
\text { Detecção de Interferências (4040) } \\
\text { Estimativa de Custo (4070) } \\
\text { Simulação em RV (4240) }\end{array}$ & \\
\hline & Construção e Fabricação (5000) & $\begin{array}{l}\text { Pré-Moldagem de Concreto (5040) } \\
\text { Logística de Construção (5050) } \\
\text { Modelagem de Chapa Metálica (5070) }\end{array}$ & \\
\hline & Operação e Manutenção (6000) & $\begin{array}{c}\text { Rastreamento de Ativos (6030) } \\
\text { Inspeção Predial (6040) }\end{array}$ & \\
\hline & Monitoramento e Controle (7000) & $\begin{array}{c}\text { BIM em Campo (7020) } \\
\text { Utilização em Tempo Real (7040) }\end{array}$ & \\
\hline & Ligação e Extensão (8000) & $\begin{array}{c}\text { Ligação BIM/ERP (8020) } \\
\text { Interface BIM/loT (8050) } \\
\text { Extensão em Serviços Web (8070) }\end{array}$ & \\
\hline
\end{tabular}

Nota: *Estudos que abordam mais de uma fase do ciclo de vida da edificação. Fonte: As autoras.

A classe de problemas relativa à Detecção e Rastreamento de Objetos Inteligentes é apresentada em dois estudos. Akanmu, Anumba e Messner (2012) desenvolvem uma solução RFID-BIM para rastrear o posicionamento/status de objetos no canteiro de obras, armazenar estas informações e integrá-las para visualização contextualizada no modelo, em uma ferramenta BIM de integração (Autodesk Navisworks). O objetivo é monitorar o progresso da produção em tempo real e verificar consistências relativas ao planejamento, para auxiliar o controle logístico e as tomadas de decisão. Niu et al. (2015) definem os conceitos e as propriedades de Objetos Inteligentes de Construção (SCO) - autonomia, consciência e capacidade de interação com o entorno. Representados virtualmente no modelo BIM, as potenciais aplicações dos SCOs abrangem: logística e gestão da cadeia de suprimentos; gestão de segurança; guia de procedimentos de fluxos de trabalho (ex. pré-fabricação); e gerenciamento de facilities.

A classe de problemas relativa à Visualização, Interação e Comunicação entre Agentes no Ambiente de Trabalho abarca dez estudos, nos quais predominam soluções RFIDBIM e aplicações voltadas para a cadeia de suprimentos, construção e gestão da qualidade. Motamedi e Hammad (2009) abordam os benefícios de rastrear, armazenar e compartilhar informações de objetos da edificação em tempo real (localização, status de instalação, inspeção e/ou manutenção), mediante uso de marcadores RFID, sincronizá-las com bancos de dados estruturados e visualizá-las de modo contextualizado com a edificação nos modelos, utilizando ferramentas BIM de integração (Graphisoft Constructor, Control e 5D Presenter). Por sua vez, Xie, Shi e Issa (2010) propõem um ambiente virtual imersivo e interativo, enriquecido com a integração RFIDBIM, para proprietários e equipes de projeto e construção. A ênfase do ambiente está na fabricação de aço e seu içamento no canteiro. As aplicações visam a aquisição de feedbacks visual e remoto do canteiro em tempo real, análise de alternativas de progresso da produção, reorganização temporária de instalações e equipamentos, e identificação de problemas de segurança. Wang et al. (2012) explanam conceitualmente a utilização integrada de modelos BIM e tecnologia de RA para aprimorar a visualização de informações em uma gama de aplicações. As aplicações visam o suporte à interação e comunicação efetiva entre os agentes, contemplando no contexto da Interface BIM/IoT a gestão e o rastreamento do fluxo de materiais com soluções integradas RFID-BIM, sendo a RA responsável por promover a visualização dessas informações no canteiro de obras em tempo real. Ikonen et al. (2013) apresentam um sistema de informação RFIDBIM, empregado no rastreamento, controle e visualização em tempo real de elementos de concreto pré-fabricado. $\mathrm{O}$ acesso é distribuído por meio de uma solução BIM (Tekla Server), dispositivos móveis e interface web. Feng et al. 
(2015) apresentam um modelo inteligente que consiste em um repositório centralizado de informações de elementos de construção na nuvem, agregado às tecnologias RFID, GPS, BIM e ao cronograma da construção. O objetivo desta solução é distribuir as informações em dispositivos móveis em tempo real, para beneficiar atividades de gerenciamento de logística e obra para construções préfabricadas com uso do modelo BIM (ex. montagem, teste e manutenção). Akanmu et al. (2015) descrevem o desenvolvimento e implementação de um sistema automatizado de geração de layouts de canteiro de obras, a partir da integração de modelos BIM (na ferramenta Autodesk Navisworks), algoritmos genéticos e RFID para rastreamento de objetos em tempo real. A convergência das tecnologias mencionadas visa maximizar a integridade dos layouts gerados. Lee et al. (2012) apresentam um sistema de navegação em tempo real para gruas, no qual o modelo BIM é integrado a sensores para auxiliar na visualização do canteiro e no manuseio do equipamento. As aplicações beneficiam a logística da construção e as atividades em campo, auxiliando os operários responsáveis e os escritórios de controle. Dave et al. (2015) explanam como a integração da IoT ao VisiLean pode ser utilizada para viabilizar a comunicação automatizada e em tempo real do modelo proposto com a gestão de recursos e os sistemas de controle de produção da construção. O modelo BIM (4D) nesse contexto atua como recurso de visualização simultânea para aprimorar a entrega de informações em todas as etapas da produção. Por fim, Li et al. (2016a) e Li et al. (2016b), estudos continuados, apresentam um modelo conceitual RFIDBIM para a reestruturação dos processos de construção de habitações pré-fabricadas, baseado em uma análise SWOT para aprimorar a gestão da produção em Hong Kong. Ademais, analisam fatores de risco associados a partes interessadas do processo de pré-fabricação. Aponta-se a solução como estratégia para facilitar a comunicação entre agentes no processo e mitigar riscos inerentes a cronogramas críticos.

\section{BIM e loT na Operação e Manutenção}

O agrupamento inerente a Operação e Manutenção (Quadro 4) abrange vinte e seis publicações e atende a sete classes de problemas: Sensibilidade à Eficiência Energética, Instrumentação e Monitoramento da Integridade Estrutural, Operações de Resposta a Emergências, Planejamento de Sistemas Inteligentes, Qualidade Ambiental Interna, Detecção e Rastreamento de Objetos Inteligentes e Visualização, Interação e Comunicação entre Agentes no Ambiente de Trabalho. A síntese de Séries e Usos do Modelo identificados nesta fase é apresentada nas Figura 7 e Figura 8, e envolve sete séries distintas associadas a trinta e dois usos do modelo. Destaca-se a demanda desta fase por Modelos de Registro e a ênfase nas séries de Monitoramento e Controle, relativa à Utilização em Tempo Real do modelo BIM; e Operação e Manutenção, associada ao Rastreamento de Ativos. Constata-se também uma gama de aplicações inerentes a Simulação e Quantificação. Reitera-se que os usos evidenciados se apresentam correlacionados à série de Ligação e Extensão, por meio da Integração BIM/FM, o emprego de Interface BIM/IoT e Extensão em Serviços Web.

Figura 7- Síntese de Séries e Usos do Modelo: estudos da fase de Operação e Manutenção (Parte 1)

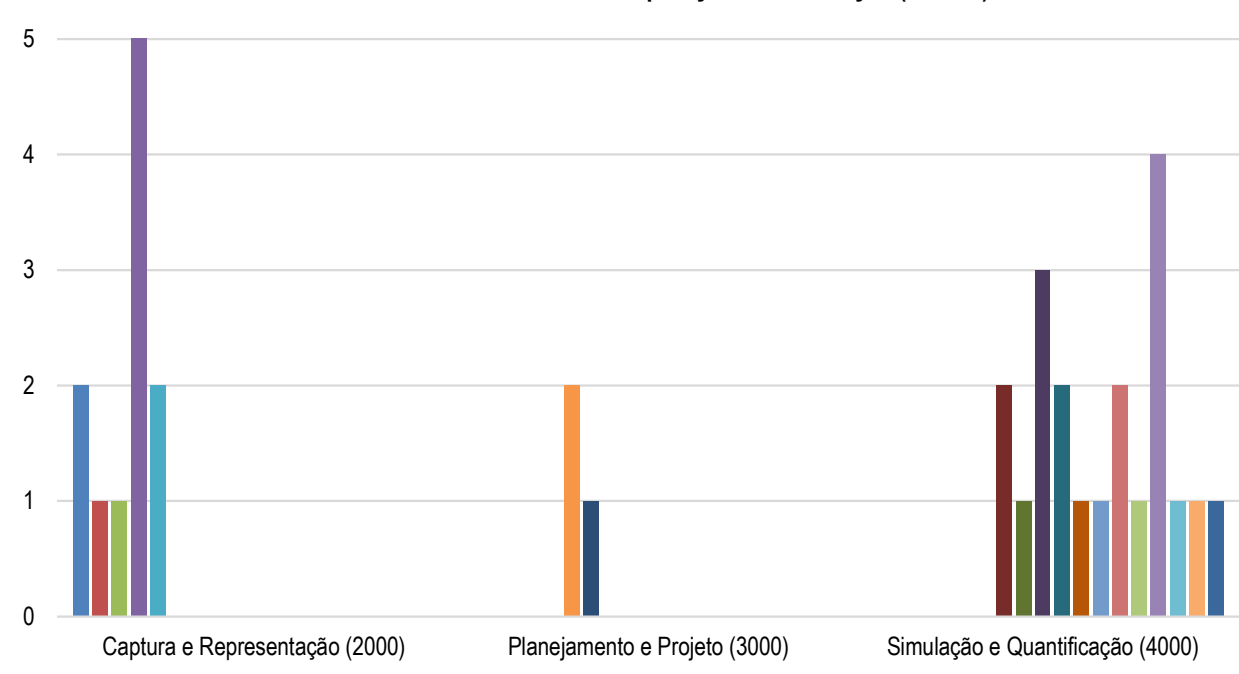


Figura 8 - Síntese de Séries e Usos do Modelo: estudos da fase de Operação e Manutenção (Parte 2)

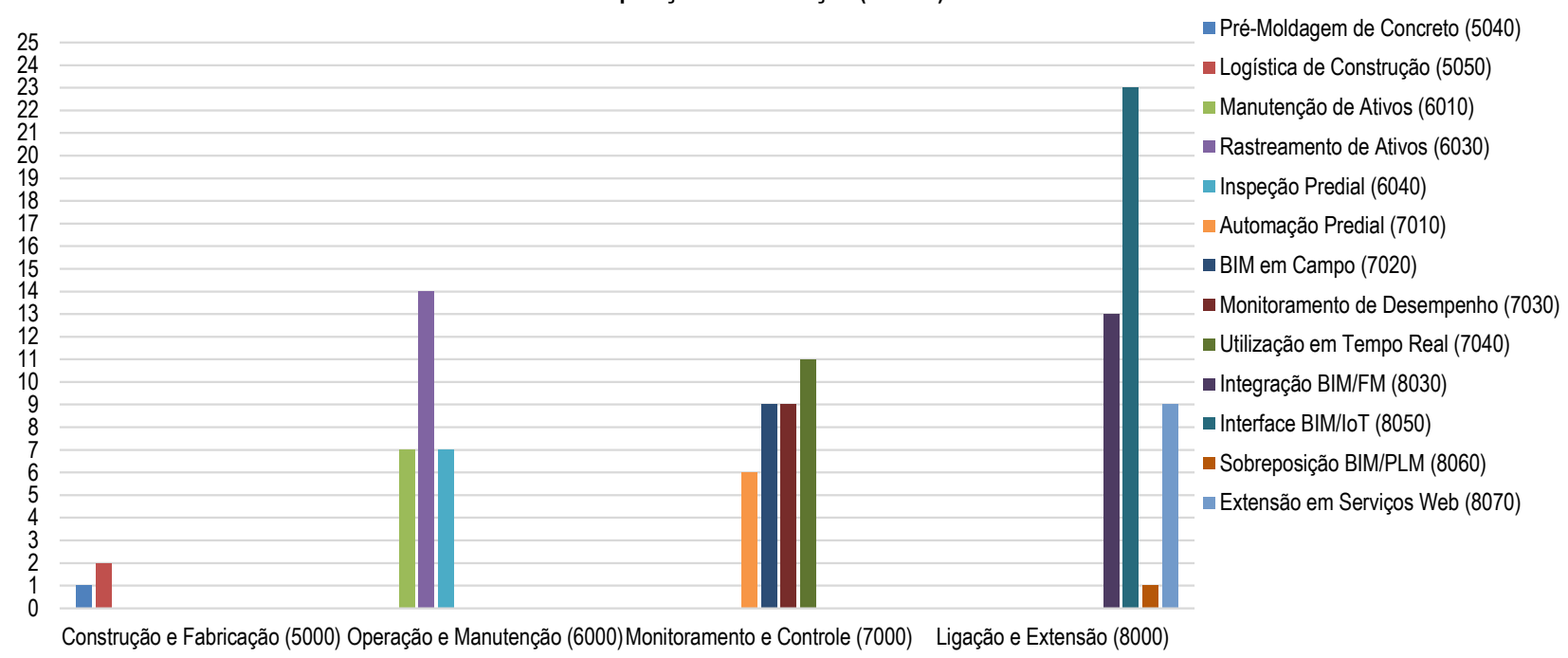

Fonte: As autoras

Quadro 4 - Integração de BIM e loT: Operação e Manutenção

\begin{tabular}{|c|c|c|c|}
\hline Quadro 4 - Integraçáo de BIM e loT: & eraçao e IManutençao & & (Contint \\
\hline Classes de Problemas & Séries de Uso do Modelo & Uso do Modelo & Referência \\
\hline \multirow{5}{*}{$\begin{array}{l}\text { Sensibilidade à Eficiência } \\
\text { Energética }\end{array}$} & Captura e Representação (2000) & Manutenção de Registros (2070) & \multirow{5}{*}{$\begin{array}{c}\text { Crosbie, Dawood e Dean (2010)* } \\
\text { Osello et al. (2013) } \\
\text { Gokçe e Gokçe }(2013) \\
\text { Gokçe e Gokçe (2014a) } \\
\text { Gokçe e Gokçe (2014b) } \\
\text { Lee, Cha e Park (2016) }\end{array}$} \\
\hline & Planejamento e Projeto (3000) & Autoria de Projeto (3040) & \\
\hline & Simulação e Quantificação (4000) & $\begin{array}{c}\text { Estimativa de Custo (4070) } \\
\text { Consumo de Energia (4090) } \\
\text { Análise de Iluminação (4120) } \\
\text { Análise de Sustentabilidade (4220) } \\
\text { Análise Térmica (4230) } \\
\text { Avaliação do Ciclo de Vida (4250) }\end{array}$ & \\
\hline & Monitoramento e Controle (7000) & $\begin{array}{c}\text { Automação Predial (7010) } \\
\text { Monitoramento de Desempenho (7030) } \\
\text { Utilização em Tempo Real (7040) }\end{array}$ & \\
\hline & Ligação e Extensão (8000) & $\begin{array}{c}\text { Integração BIM/FM (8030) } \\
\text { Interface BIM/loT (8050) } \\
\text { Extensão em Serviços Web (8070) }\end{array}$ & \\
\hline \multirow{5}{*}{$\begin{array}{l}\text { Instrumentação e Monitoramento da } \\
\text { Integridade Estrutural }\end{array}$} & Captura e Representação (2000) & Manutenção de Registros (2070) & \multirow{5}{*}{$\begin{array}{l}\text { Rio, Ferreira e Poças-Martins (2013) } \\
\text { Zhang e Bai (2015) }\end{array}$} \\
\hline & Simulação e Quantificação (4000) & Análise Estrutural (4210) & \\
\hline & Operação e Manutenção (6000) & $\begin{array}{l}\text { Rastreamento de Ativos (6030) } \\
\text { Inspeção Predial (6040) }\end{array}$ & \\
\hline & Monitoramento e Controle (7000) & $\begin{array}{l}\text { Monitoramento de Desempenho (7030) } \\
\text { Utilização em Tempo Real (7040) }\end{array}$ & \\
\hline & Ligação e Extensão (8000) & Interface BIM/loT (8050) & \\
\hline \multirow{5}{*}{$\begin{array}{l}\text { Operações de Resposta a } \\
\text { Emergências }\end{array}$} & Captura e Representação (2000) & Manutenção de Registros (2070) & \multirow{5}{*}{$\begin{array}{l}\text { Rueppel e Stuebbe (2008) } \\
\text { Li et al. (2014) } \\
\text { Li, Becerick-Gerber e Soibelman (2014) }\end{array}$} \\
\hline & Simulação e Quantificação (4000) & Análise Espacial (4200) & \\
\hline & Operação e Manutenção (6000) & Rastreamento de Ativos (6030) & \\
\hline & Monitoramento e Controle (7000) & $\begin{array}{c}\text { BIM em Campo (7020) } \\
\text { Utilização em Tempo Real (7040) }\end{array}$ & \\
\hline & Ligação e Extensão (8000) & $\begin{array}{c}\text { Interface BIM/loT (8050) } \\
\text { Extensão em Serviços Web (8070) }\end{array}$ & \\
\hline \multirow[b]{2}{*}{$\begin{array}{l}\text { Planejamento de Sistemas } \\
\text { Inteligentes }\end{array}$} & Captura e Representação (2000) & Comunicação Visual (2090) & \multirow[b]{2}{*}{$\begin{array}{l}\text { Boyes (2015) } \\
\text { Tomasi et al. (2015) }\end{array}$} \\
\hline & Ligação e Extensão (8000) & $\begin{array}{c}\text { Integração BIM/FM (8030) } \\
\text { Interface BIM/loT (8050) } \\
\text { Extensão em Serviços Web (8070) }\end{array}$ & \\
\hline \multirow{5}{*}{ Qualidade Ambiental Interna } & Captura e Representação (2000) & Manutenção de Registros (2070) & \multirow{5}{*}{$\begin{array}{l}\text { Marzouk e Abdelaty (2014a) } \\
\text { Marzouk e Abdelaty (2014b) } \\
\text { Habibi (2016) }\end{array}$} \\
\hline & Simulação e Quantificação (4000) & $\begin{array}{l}\text { Análise de lluminação (4120) } \\
\text { Análise Solar (4190) } \\
\text { Análise Térmica (4230) } \\
\text { Estudos de Ventilação (4260) }\end{array}$ & \\
\hline & Operação e Manutenção (6000) & $\begin{array}{l}\text { Manutenção de Ativos (6010) } \\
\text { Inspeção Predial (6040) }\end{array}$ & \\
\hline & Monitoramento e Controle (7000) & Monitoramento de Desempenho (7030) & \\
\hline & Ligação e Extensão (8000) & $\begin{array}{c}\text { Integração BIM/FM (8030) } \\
\text { Interface BIM/loT (8050) }\end{array}$ & \\
\hline
\end{tabular}




\begin{tabular}{|c|c|c|c|}
\hline & Séries de Uso do Modelo & Uso do Modelo & \\
\hline \multirow{7}{*}{$\begin{array}{l}\text { Detecção e Rastreamento de } \\
\text { Objetos Inteligentes }\end{array}$} & & Representação As-Constructed (2030) & \multirow{7}{*}{$\begin{array}{c}\text { Akanmu, Anumba e Messner (2012) } \\
\text { Motamedi, Soltani e Hammad (2013) } \\
\text { Gai, Azadmanesh e Rezaeian (2015) } \\
\text { Valero, Adan e Bosche (2015) } \\
\text { Motamedi et al. (2015) } \\
\text { Niu et al. }(2015)^{\star}\end{array}$} \\
\hline & Captura e Representação (2000) & $\begin{array}{c}\text { Escaneamento a Laser (2050) } \\
\text { Fotogrametria (2060) }\end{array}$ & \\
\hline & Planejamento e Projeto (3000) & Planejamento da Construção (3020) & \\
\hline & Construção e Fabricação (5000) & $\begin{array}{l}\text { Pré-Moldagem de Concreto (5040) } \\
\text { Logística de Construção (5050) }\end{array}$ & \\
\hline & Operação e Manutenção (6000) & $\begin{array}{l}\text { Manutenção de Ativos (6010) } \\
\text { Rastreamento de Ativos (6030) } \\
\text { Inspeção Predial (6040) }\end{array}$ & \\
\hline & Monitoramento e Controle (7000) & $\begin{array}{c}\text { BIM em Campo (7020) } \\
\text { Utilização em Tempo Real (7040) }\end{array}$ & \\
\hline & Ligação e Extensão (8000) & $\begin{array}{c}\text { Integração BIM/FM (8030) } \\
\text { Interface BIM/loT (8050) } \\
\text { Extensão em Serviços Web (8070) }\end{array}$ & \\
\hline \multirow{7}{*}{$\begin{array}{l}\text { Visualização, Interação e } \\
\text { Comunicação entre Agentes no } \\
\text { Ambiente de Trabalho }\end{array}$} & Captura e Representação (2000) & $\begin{array}{c}\text { Manutenção de Registros (2070) } \\
\text { Comunicação Visual (2090) }\end{array}$ & \multirow{7}{*}{$\begin{array}{l}\text { Motamedi e Hammad (2009)* } \\
\text { Motamedi et al. (2011) } \\
\text { Lee e Akin (2011) } \\
\text { Olbrich et al. (2013) }\end{array}$} \\
\hline & Planejamento e Projeto $(3000)$ & Planejamento da Construção (3020) & \\
\hline & Simulação e Quantificação (4000) & $\begin{array}{c}\text { Simulação em RA (4030) } \\
\text { Simulação em Realidade Virtual (4240) }\end{array}$ & \\
\hline & Construção e Fabricação (5000) & Logística de Construção (5050) & \\
\hline & Operação e Manutenção (6000) & $\begin{array}{l}\text { Manutenção de Ativos (6010) } \\
\text { Rastreamento de Ativos (6030) } \\
\text { Inspeção Predial (6040) }\end{array}$ & \\
\hline & Monitoramento e Controle (7000) & $\begin{array}{c}\text { Automação Predial (7010) } \\
\text { BIM em Campo (7020) } \\
\text { Utilização em Tempo Real (7040) }\end{array}$ & \\
\hline & Ligação e Extensão (8000) & $\begin{array}{c}\text { Integração BIM/FM (8030) } \\
\text { Interface BIM/loT (8050) } \\
\text { Sobreposição BIM/PLM (8060) } \\
\text { Extensão em Serviços Web }(8070)\end{array}$ & \\
\hline
\end{tabular}

Nota: *Estudos que abordam mais de uma fase do ciclo de vida da edificação. Fonte: As autoras.

A classe de problemas relativa à Sensibilidade à Eficiência Energética é abordada em seis estudos. Em Osello et al. (2013), os autores elaboram uma infraestrutura baseada na web para exibir informações de consumo de energia, coletadas por sensores ambientais. O modelo BIM e soluções de interoperabilidade são utilizados para processar dados e promover a contextualização semântica das informações, abarcando aplicações tanto para simulações de consumo como para gerenciamento de facilities. Os estudos de Gokçe e Gokçe (2013, 2014a, 2014b) apresentam um sistema desenvolvido para processar dados e analisar informações de desempenho de múltiplas fontes para monitoramento e controle inteligente da edificação, visando à redução do consumo de energia na fase de O\&M. Gokçe e Gokçe (2014a) acrescentam às fontes os dados simulados de energia adquiridos desde o projeto através do modelo BIM, para efeito comparativo com as informações extraídas da coleta de dados do ambiente físico - no sentido de subsidiar estratégias de operação da edificação. É uma lógica semelhante à utilizada por Crosbie, Dawood e Dean (2010) ao conceber seu modelo de operação, conforme explicitado anteriormente na fase de Planejamento/Programa e Projeto. Por fim, Lee, Cha e Park (2016) apresentam uma plataforma integrada de monitoramento e controle na web tendo em vista a eficiência energética dos edifícios. Sensores, medidores e sistemas de automação são responsáveis por coletar e transmitir dados em tempo real, habilitando a extração de informações de consumo. O modelo BIM, por sua vez, é utilizado como método eficaz de visualizar espacialmente estas informações vinculadas à localização da edificação.

A classe de problemas relativa à Instrumentação e Monitoramento da Integridade Estrutural é abordada em dois estudos. Rio, Ferreira e Poças-Martins (2013) exploram meios de modelar sistemas de manutenção da integridade estrutural, que abrangem dados de comportamento estrutural coletados da edificação (ex. segurança, integridade, desempenho, detecção de danos) e BIM como padrão de gerenciamento de informações. Para tanto, os autores avaliam o uso do schema Industry Foundation Classes (IFC) no processo de integração do modelo com o ambiente físico, para exibir tais informações em ferramentas BIM de integração (Solibri Model Viewer). Além disso, avalia-se o emprego do schema em ferramentas de análise estrutural. Por sua vez, Zhang e Bai (2015) apresentam um sistema sem fio de escaneamento de condições estruturais baseado em tecnologia de sensores de deformação, BIM e RFID. O objetivo do sistema é permitir o escaneamento da deformação estrutural sem contato e apontá-lo no elemento estrutural correspondente do modelo em uma ferramenta BIM de autoria (Autodesk Revit), de modo a fornecer sinais de alerta para os engenheiros e demais tomadores de decisão. As aplicações abarcam monitoramento, prognóstico e gerenciamento da saúde de 
infraestruturas civis, especialmente para inspeção rápida de condições estruturais pós-risco.

A classe de problemas relativa às Operações de Resposta a Emergências é abordada em três estudos. Rueppel e Stuebbe (2008) apresentam o modelo de uma plataforma de navegação para ambientes internos, acessada via dispositivos móveis. Essa plataforma consiste no uso das tecnologias RFID, Ultra Wide Band (UWB) e WLAN integradas ao modelo BIM, que atua como repositório de informações de edificações públicas (ex. contexto espacial). A solução contribui para orientação e segurança de socorristas, viabilizando posicionamento, cálculo e visualização de rotas de fuga. Li et al. (2014) e Li, Becerick-Gerber e Soibelman (2014), estudos continuados, tratam de soluções envolvendo tecnologias de Radio Frequência (ex. BLE) e BIM, na qual o modelo é integrado a um sistema de rastreamento de socorristas e ocupantes para: (i) análise espacial; (ii) fornecimento de informações geométricas das áreas sensoriadas; e (iii) atuação como interface do usuário para monitoramento e visualização em tempo real. As aplicações visam facilitar o trabalho de equipes de emergência.

A classe de problemas relativa à Planejamento de Sistemas Inteligentes é contemplada por dois estudos. Tomasi et al. (2015) apresentam uma solução RSSF-BIM utilizando a tecnologia UWB para posicionamento em ambientes internos. O intuito é auxiliar no desenvolvimento da RSSF, contexto no qual os autores destacam que a geometria e informações relevantes disponíveis no modelo BIM podem beneficiar tarefas relacionadas à IoT nas fases de planejamento e comissionamento da RSSF - caso a interoperabilidade entre as ferramentas funcione. As aplicações devem beneficiar desenvolvedores, especialistas e usuários BIM. Por sua vez, Boyes (2015) define segurança e privacidade, com ênfase na vulnerabilidade de uso do modelo BIM, enquanto base centralizada de informações de registros da edificação, integrado a tecnologias facilitadoras da IoT para gerenciamento de facilities.

A classe de problemas relativa à Qualidade Ambiental Interna agrega os estudos de Marzouk e Abdelaty (2014a, 2014b) e Habibi (2016). O primeiro grupo de autores apresenta uma solução RSSF-BIM para monitorar as condições térmicas (temperatura e umidade) e a concentração de partículas em suspensão de estações de metrô. Empregando-se uma ferramenta BIM de autoria (Autodesk Revit), o modelo é utilizado para aprimorar a visualização de informações fornecidas pela RSSF e por dispositivos específicos de medição. As aplicações visam ampliar o conhecimento de operadores das estações em relação aos espaços que tendem a ter problemas de conforto térmico. Os benefícios se estendem à manutenção de ativos, especialmente de equipamentos HVAC, por fornecer informações necessárias para ações preventivas. Já Habibi (2016) elabora um sistema de monitoramento em tempo real para atingir condições de conforto ótimas nos contextos de desempenho e satisfação dos usuários. Esse sistema explora o uso do modelo BIM em simulações preditivas para extrair informações ambientais de referência. Essas informações são comparadas com aquelas coletadas por RSSF e visualizadas graficamente em MATLAB, através de monitores. As aplicações visam influenciar o comportamento dos usuários e aprimorar estratégias existentes de operação em cenários de retrofit.

A classe de problemas relativa à Detecção e Rastreamento de Objetos Inteligentes é atendida por cinco estudos. Motamedi, Soltani e Hammad (2013) e Motamedi et al. (2015) investigam métodos de rastreamento de ativos em ambientes internos para favorecer agentes como gerentes de facilities, inspetores prediais e ocupantes, através de soluções RFID-BIM. Para tanto, marcadores RFID são anexados aos objetos, com informações (ex. localização, data de inspeção) sincronizadas e/ou extraídas do modelo BIM. O uso do schema IFC na solução é abordado no estudo mais recente. $\mathrm{O}$ acesso às informações armazenadas é realizado por meio de aplicativos móveis e/ou de forma contextualizada no modelo. Valero, Adan e Bosche (2015) apresentam um algoritmo de processamento de dados integrado às tecnologias de escaneamento a laser e RFID para gerar modelos 3D semânticos detalhados e precisos de ambientes internos habitados. Os marcadores RFID anexados aos objetos fornecem acesso a informações armazenadas no banco de dados de sistemas digitais de FM da edificação. O objetivo é tornar o processo de geração automatizada de modelos de registro BIM rápido, preciso e robusto. Gai, Azadmanesh e Rezaeian (2015) apresentam uma abordagem híbrida para aplicação em ambientes internos. As informações inerentes ao modelo BIM são utilizadas para indicar a localização espacial $3 \mathrm{D}$ de sensores de rastreamento. Por fim, Niu et al. (2015), conforme apresentado na fase de Construção e Comissionamento, explana/aplica os SCOs.

A classe de problemas relativa à Visualização, Interação e Comunicação entre Agentes é atendida por quatro estudos. Motamedi e Hammad (2009) e Motamedi et al. (2011) são estudos continuados que, conforme indicado na fase de Construção e Comissionamento, abordam soluções RFIDBIM para rastreamento e acesso a informações de pessoal e objetos da edificação. No caso de O\&M, os autores explicam os benefícios associados a ocupantes, seguranças, bombeiros, inspetores prediais e equipes de manutenção. Lee e Akin (2012) apresentam a problemática de O\&M em coletar diversos tipos de dados para localizar/diagnosticar adequadamente equipamentos e instalações. Os autores desenvolvem um sistema para fornecer informações extraídas dessa coleta just-in-time, 
baseado no modelo BIM (geometria e informações do empreendimento), nas ferramentas de FM (informações de manutenção), no sistema de Automação Predial (BACnet) e na tecnologia de RA - para aprimorar a eficiência do trabalho de campo com a integração e visualização de uma gama de informações em tempo real. Finalmente, Olbrich et al. (2013) apresentam uma solução web distribuída em dispositivos móveis que integra, em tempo real, BIM, tecnologias de RA e rastreamento para suporte às atividades de manutenção. A solução, enriquecida por uma funcionalidade de anotações semânticas, pode ser aplicada tanto em ambientes externos como internos.

\section{BIM e loT na Demolição ou Descarte}

A fase de Demolição ou Descarte (Quadro 5) agrega dois estudos inerentes à classe de problemas Visualização, Interação e Comunicação entre Agentes no Ambiente de Trabalho. Motamedi e Hammad (2009), conforme indicado nas fases anteriores, abordam soluções RFIDBIM para rastreamento e acesso a informações de objetos da edificação. No caso de Demolição e Descarte, os autores apontam benefícios voltados para o gerenciamento do fim da vida de objetos e manufatura reversa. Já Ness et al. (2014) propõem um sistema conceitual de reuso de elementos estruturais de aço a partir de uma solução RFID-BIM, que permite o monitoramento das peças por todo o ciclo de vida, até o momento da desconstrução. A aplicação do sistema visa beneficiar empresas de estrutura metálica na gestão da informação para reuso destas peças em novas edificações. Os benefícios se estendem às tomadas de decisão sustentáveis, quando a especificação de materiais de reuso é praticada em projeto e a instalação influencia na logística de construção. Destaca-se, nesse âmbito, o uso do modelo para Sobreposição BIM/PLM (Ligação e Extensão) - que envolve o gerenciamento do ciclo de vida de um produto e seus impactos.

\section{BIM e loT Atemporal}

Underwood e Isikdag (2011) - única publicação atemporal da amostra - aborda a evolução do modelo BIM mediada por TICs. Entre as tecnologias discriminadas, os autores enfatizam como a integração de RSSF ao modelo deve contribuir para uma relação mais consistente de BIM e IoT.

\section{Discussão}

Diante da sumarização de resultados da RSL, é possível compreender os principais propósitos da integração de BIM e IoT e suas variações de aplicação. Em relação à IoT, pode-se afirmar que se trata de uma convergência de tecnologias de sensoriamento, informação e comunicação responsável pela aquisição, processamento e agregação de dados coletados do ambiente físico em tempo real, para transformação em informação e conhecimento. Por sua vez, em relação ao BIM, considera-se 3 atribuições gerais: a primeira associada à Camada de Serviço e as demais associadas à Camada de Interface da IoT.

São atribuições do BIM:

(1) atuar como estrutura virtual de dados da edificação, no sentido de dar suporte à classificação e associação de dados sensoriados do ambiente físico com dados geométricos e não geométricos armazenados em objetos virtuais, e auxiliar na geração e extração de informações contextualizadas semanticamente;

(2) subsidiar simulações de desempenho e análises preditivas, para confrontar dados sensoriados do ambiente físico com dados simulados, e fundamentar linhas de referência para o estabelecimento de regras e estratégias de projeto, construção e operação; e

(3) exercer o papel protagonista de visualizador da informação, proporcionando a contextualização semântica e espacial das informações integradas.

Quadro 5 - Integração de BIM e loT: Demolição ou Descarte

\begin{tabular}{|c|c|c|c|}
\hline Classes de Problemas & Séries de Uso do Modelo & Usos do Modelo & Referência \\
\hline \multirow{7}{*}{$\begin{array}{c}\text { Visualização, Interação e Comunicação entre } \\
\text { Agentes no Ambiente de Trabalho }\end{array}$} & Captura e Representação (2000) & Manutenção de Registros (2070) & \multirow{7}{*}{$\begin{array}{c}\text { Motamedi e Hammad (2009)* } \\
\text { Ness et al. }(2014)\end{array}$} \\
\hline & Planejamento e Projeto (3000) & $\begin{array}{l}\text { Planejamento da Construção (3020) } \\
\text { Seleção e Especificação (3090) }\end{array}$ & \\
\hline & Simulação e Quantificação (4000) & $\begin{array}{l}\text { Análise de Sustentabilidade (4220) } \\
\text { Avaliação do Ciclo de Vida (4250) }\end{array}$ & \\
\hline & Construção e Fabricação (5000) & $\begin{array}{c}\text { Logística de Construção (5050) } \\
\text { Modelagem de Chapa Metálica (5070) }\end{array}$ & \\
\hline & Operação e Manutenção (6000) & $\begin{array}{l}\text { Manutenção de Ativos (6010) } \\
\text { Aquisição de Ativos (6020) } \\
\text { Rastreamento de Ativos (6030) } \\
\text { Inspeção Predial (6040) }\end{array}$ & \\
\hline & Monitoramento e Controle (7000) & $\begin{array}{c}\text { BIM em Campo (7020) } \\
\text { Utilização em Tempo Real (7040) }\end{array}$ & \\
\hline & Ligação e Extensão (8000) & $\begin{array}{c}\text { Integração BIM/FM (8030) } \\
\text { Interface BIM/loT (8050) } \\
\text { Sobreposição BIM/PLM (8060) } \\
\text { Extensão em Serviços Web }(8070)\end{array}$ & \\
\hline
\end{tabular}

Nota: *Estudos que abordam mais de uma fase do ciclo de vida da edificação. Fonte: As autoras. 
$\mathrm{O}$ agrupamento dos estudos nas quatro fases do ciclo de vida subsidiou a identificação dos usos do modelo BIM mais recorrentes para as atribuições retratadas. $\mathrm{Na}$ fase de Planejamento/Programa e Projeto, destacam-se os usos do modelo em análises de iluminação, insolação e consumo de energia (Série de Simulação e Quantificação) para dar suporte à concepção e autoria de projeto. A integração de BIM e IoT atua nas etapas iniciais do processo e/ou em cenários de retrofit, viabilizando o diálogo entre protótipos físicos e virtuais, além de possibilitar análises espaciais para o planejamento de sistemas inteligentes. $\mathrm{Na}$ fase de Construção e Comissionamento, destacam-se os usos do modelo em campo e em tempo real (Série de Monitoramento e Controle), voltado para o rastreamento de ativos (Série de O\&M) e logística de construção (Série de Construção e Fabricação). A integração de BIM e IoT envolve estes usos agregados às tecnologias RSSF, RFID e BLE e assegura a informação distribuída por meio da extensão em serviços web (Série de Ligação e Extensão). $\mathrm{Na}$ fase de Operação e Manutenção, a ênfase está na Série de Monitoramento e Controle por meio de usos associados à automação predial, monitoramento de desempenho e utilização do modelo BIM em tempo real. As tecnologias de RSSF e RFID são as mais recorrentes nos usos indicados. Por outro lado, são constatados diversos tipos de simulações preditivas para estabelecer linhas de referência de desempenho da edificação, e novamente identifica-se a relevância da informação distribuída entre agentes via web. Na fase de Demolição ou Descarte destaca-se o uso do modelo integrado ao gerenciamento do ciclo de vida de um produto, e o rastreamento deste produto por meio de tecnologias como RFID.

Entre as fases destacadas, foram mapeadas nove classes de problemas que tendem a resoluções provenientes da integração de BIM e IoT (Quadro 6). A classe que mais concentra investigações científicas é Visualização,
Interação e Comunicação entre Agentes no Ambiente de Trabalho - com catorze estudos. De acordo com a ótica da Design Science Research (DSR) (DRESCH; LACERDA; ANTUNES JUNIOR, 2015), quatro classes de problemas sinalizam linhas de pesquisa mais desenvolvidas: Sensibilidade à Eficiência Energética, Gestão de Saúde e Segurança no Ambiente de Trabalho, Detecção e Rastreamento de Objetos Inteligentes e Visualização, Interação e Comunicação entre Agentes no Ambiente de Trabalho. Essa lógica consiste no fato destas linhas agregarem todos os tipos de artefato da DSR - constructo, modelo, método e instanciação. Concepção e Autoria de Projetos apresenta-se em estado inicial de investigação, por conter somente artefatos de método e instanciação.

Além disso, observam-se quatro classes de problemas que atendem a mais de uma fase do ciclo de vida da edificação: Sensibilidade à Eficiência Energética; Planejamento de Sistemas Inteligentes; Detecção e Rastreamento de Objetos Inteligentes; e Visualização, Interação e Comunicação entre Agentes no Ambiente de Trabalho. Essas classes apontam para a interação e/ou continuidade de usos do modelo BIM entre os agentes (projetistas, fornecedores, agentes que atuam no canteiro de obras, gerentes de facilities, proprietários, ocupantes). As demais classes explanam aplicações específicas de uma fase do ciclo e consistem em investigações isoladas envolvendo agentes de um determinado contexto. Portanto, constatase no processo de integração uma variedade de agentes beneficiados por este vetor de evolução pertinente ao postBIM (Quadro 6).

Por fim, a Figura 9 apresenta os países pioneiros na temática da integração de BIM e IoT, considerando a instituição de vínculo do primeiro autor de cada estudo. Foram mapeados doze países na amostra, com destaque em número de publicações para o grupo de instituições sediadas nos Estados Unidos.

\begin{tabular}{|c|c|c|c|c|}
\hline \multicolumn{5}{|c|}{ Quadro 6 - Integração de BIM e loT: Classes de Problemas } \\
\hline Classes de Problemas & Descrição & Agentes & Fases do Ciclo de Vida & Artefatos \\
\hline $\begin{array}{l}\text { Sensibilidade à Eficiência } \\
\text { Energética }\end{array}$ & $\begin{array}{c}\text { Elaboração de estratégias baseadas em } \\
\text { desempenho visando à redução do consumo de } \\
\text { energia da edificação }\end{array}$ & $\begin{array}{l}\text { Projetistas; Inspetores Prediais; Gerentes de } \\
\text { Facilities; Proprietários; Ocupantes }\end{array}$ & $\begin{array}{l}\text { Planejamento/Programa e } \\
\text { Projeto } \\
\text { Operação e Manutenção }\end{array}$ & $\begin{array}{l}\text { Constructo } \\
\text { Modelo } \\
\text { Método } \\
\text { Instanciação }\end{array}$ \\
\hline $\begin{array}{l}\text { Planejamento de Sistemas } \\
\text { Inteligentes }\end{array}$ & $\begin{array}{c}\text { Planejamento e projeto integrado de redes de } \\
\text { sensores e arquitetura visando ambientes } \\
\text { inteligentes } \\
\text { Elaboração de soluções de segurança e } \\
\text { privacidade visando ambientes inteligentes }\end{array}$ & $\begin{array}{l}\text { Projetistas; Desenvolvedores/Integradores; } \\
\text { Gerentes de Facilities; Vigilantes; Ocupantes }\end{array}$ & $\begin{array}{l}\text { Planejamento/Programa e } \\
\text { Projeto } \\
\text { Operação e Manutenção }\end{array}$ & $\begin{array}{l}\text { Constructo } \\
\text { Método } \\
\text { Instanciação }\end{array}$ \\
\hline Qualidade Ambiental Interna & $\begin{array}{l}\text { Simulação e monitoramento de parâmetros } \\
\text { ambientais para assegurar a qualidade em } \\
\text { ambientes internos visando satisfação dos } \\
\text { usuários e desempenho de energia }\end{array}$ & Projetistas; Gerentes de Facilities; Ocupantes & Operação e Manutenção & $\begin{array}{l}\text { Modelo } \\
\text { Método } \\
\text { Instanciação }\end{array}$ \\
\hline $\begin{array}{l}\text { Concepção e Autoria de } \\
\text { Projetos }\end{array}$ & $\begin{array}{l}\text { Integração de modelos físicos e virtuais via } \\
\text { monitoramento e controle para suporte à } \\
\text { concepção e autoria de projetos }\end{array}$ & Projetistas & $\begin{array}{l}\text { Planejamento/Programa e } \\
\text { Projeto }\end{array}$ & $\begin{array}{c}\text { Método } \\
\text { Instanciação }\end{array}$ \\
\hline $\begin{array}{l}\text { Gestão de Saúde e Segurança } \\
\text { no Ambiente de Trabalho }\end{array}$ & $\begin{array}{l}\text { Monitoramento de condições ambientais no } \\
\text { ambiente de trabalho } \\
\text { Rastreamento e monitoramento de pessoal, fluxos } \\
\text { de trabalho e logística no canteiro de obras }\end{array}$ & $\begin{array}{c}\text { Gerentes de Obra; Gerentes de Saúde e } \\
\text { Segurança no Trabalho; Gerentes de } \\
\text { Contrato }\end{array}$ & $\begin{array}{l}\text { Construção e } \\
\text { Comissionamento }\end{array}$ & $\begin{array}{l}\text { Constructo } \\
\text { Modelo } \\
\text { Método } \\
\text { Instanciação }\end{array}$ \\
\hline
\end{tabular}




\begin{tabular}{|c|c|c|c|c|}
\hline Clacses de Problemas & & & & \\
\hline Classes de Problemas & Descriçao & Agentes & rases do Ciclo de vida & Artefatos \\
\hline $\begin{array}{l}\text { Detecção e Rastreamento de } \\
\text { Objetos Inteligentes }\end{array}$ & $\begin{array}{c}\text { Atribuição de inteligência e novas propriedades a } \\
\text { objetos para aplicações nas diversas fases do } \\
\text { ciclo de vida da edificação }\end{array}$ & $\begin{array}{l}\text { Operários; Gerentes de Projeto; Gerentes da } \\
\text { Produção; Gerentes de Obra; Gerentes de } \\
\text { Saúde e Segurança no Trabalho; Inspetores } \\
\text { Prediais; Fornecedores; Gerentes de } \\
\text { Facilities; Vigilantes; Ocupantes }\end{array}$ & $\begin{array}{c}\text { Construção e } \\
\text { Comissionamento } \\
\text { Operação e Manutenção }\end{array}$ & $\begin{array}{l}\text { Constructo } \\
\text { Modelo } \\
\text { Método } \\
\text { Instanciação }\end{array}$ \\
\hline $\begin{array}{c}\text { Visualização, Interação e } \\
\text { Comunicação entre Agentes no } \\
\text { Ambiente de Trabalho }\end{array}$ & $\begin{array}{c}\text { Aplicação de TICs nas diversas atividades de } \\
\text { Canteiro de Obras e de O\&M para ampliar } \\
\text { eficiência e produtividade }\end{array}$ & $\begin{array}{c}\text { Projetistas; Gerentes de Projeto; Operários; } \\
\text { Empreiteiros/Subempreiteiros; Gerentes da } \\
\text { Produção; Gerentes de Obra; Gerentes de } \\
\text { Contrato; Inspetores Prediais; Fornecedores; } \\
\text { Gerentes de Facilities; Vigilantes; Ocupantes; } \\
\text { Proprietários }\end{array}$ & $\begin{array}{l}\text { Construção e } \\
\text { Comissionamento } \\
\text { Operação e Manutenção } \\
\text { Demolição ou Descarte }\end{array}$ & $\begin{array}{l}\text { Constructo } \\
\text { Modelo } \\
\text { Método } \\
\text { Instanciação }\end{array}$ \\
\hline $\begin{array}{c}\text { Instrumentação e } \\
\text { Monitoramento da Integridade } \\
\text { Estrutural } \\
\end{array}$ & $\begin{array}{c}\text { Instrumentação e monitoramento da integridade } \\
\text { estrutural para suporte às atividades de } \\
\text { manutenção da edificação }\end{array}$ & Gerentes de Facilities & Operação e Manutenção & $\begin{array}{c}\text { Constructo } \\
\text { Modelo } \\
\text { Instanciação }\end{array}$ \\
\hline $\begin{array}{c}\text { Operações de Resposta a } \\
\text { Emergências }\end{array}$ & $\begin{array}{c}\text { Rastreamento em ambientes internos para } \\
\text { operações de resposta a emergências (ex. contra } \\
\text { incêndio) }\end{array}$ & Socorristas; Ocupantes & Operação e Manutenção & $\begin{array}{c}\text { Modelo } \\
\text { Método } \\
\text { Instanciação }\end{array}$ \\
\hline
\end{tabular}

Fonte: As autoras.

Figura 9 - Países que sediam as instituições pioneiras na abordagem BIM-loT

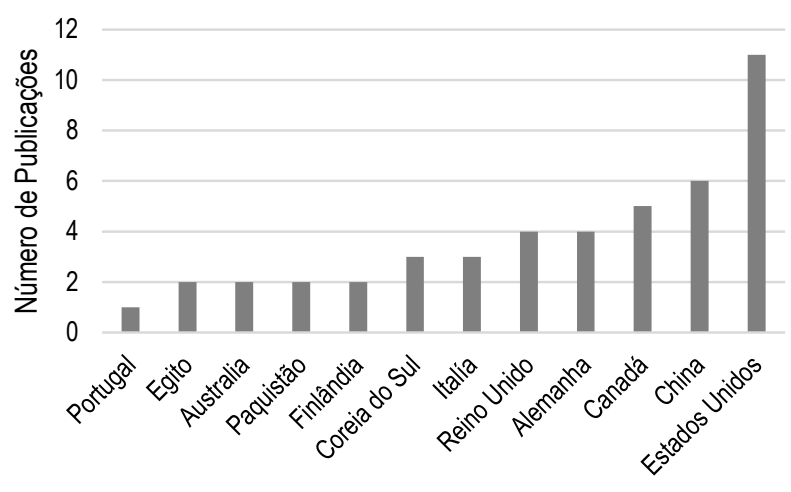

Países

Fonte: As autoras.

\section{Considerações Finais}

Este artigo visou identificar e analisar os artefatos existentes na literatura, publicados em periódicos entre 2000 e 2016, que abordam a integração de BIM e IoT a partir de uma RSL efetuada nas bases de dados SCOPUS, Compendex, ASCE Library e Web of Science. Foram identificados artefatos majoritariamente concentrados na fase de Operação e Manutenção. Por outro lado, foi constatado o interesse crescente pela integração em Construção e Comissionamento, devido ao predomínio de publicações nesta fase em 2016. Os artefatos mais disseminados consistiram em modelos e instanciações.

No processo de classificação dos estudos, foram mapeadas nove classes de problemas e apontado o envolvimento de diferentes agentes. Sensibilidade à Eficiência Energética, Planejamento de Sistemas Inteligentes, Detecção e Rastreamento de Objetos Inteligentes, e Visualização, Interação e Comunicação entre Agentes no Ambiente de Trabalho foram classes que permearam mais de uma fase do ciclo de vida. As demais se voltaram para aplicações específicas. Sensibilidade à Eficiência Energética, Gestão da Saúde e Segurança no Ambiente de Trabalho, Detecção e Rastreamento de Objetos Inteligentes e Visualização, Interação e Comunicação entre Agentes no Ambiente de Trabalho foram consideradas as linhas de pesquisa mais desenvolvidas. Já a classe de problemas relativa à Concepção e Autoria de Projeto encontra-se em estágio inicial de investigação. Finalmente, a integração aponta o propósito da IoT em adquirir, processar e agregar dados coletados do ambiente físico em tempo real, para sua transformação em informação e conhecimento. Os propósitos do BIM envolvem: atuar como estrutura virtual de dados da edificação; subsidiar simulações de desempenho e análises preditivas; e exercer o papel protagonista de visualizador da informação. Logo, compreende-se que a integração de BIM e IoT não é incipiente e encontra-se em pleno desenvolvimento, sendo observado para tanto grande demanda por programação computacional. O estágio post-BIM é um indicador de novos campos de pesquisa, nos quais a modelagem da informação da construção transcende para um contexto multidisciplinar, abarcando soluções específicas de TICs que devem ampliar as relações estáticas ou dinâmicas entre os ambientes físico e virtual.

\section{Agradecimentos}

Agradecimentos à Coordenação de Aperfeiçoamento de Pessoal de Nível Superior (CAPES) pela bolsa de mestrado e ao Conselho Nacional de Desenvolvimento Científico e Tecnológico $(\mathrm{CNPq})$ pela bolsa de produtividade em pesquisa das autoras. 


\section{Notas}

(1) Os objetos BIM representam virtualmente características físico-funcionais da edificação e viabilizam a aquisição, interpretação e análise de dados e informações geométricas e não geométricas pelo usuário e por um conjunto de aplicações (NBIMS, 2006).

(2) A Web Semântica é uma web de informação qualificada, derivada de dados através de uma teoria semântica para interpretar os símbolos (SHADBOLT; BERNERS-LEE; HALL, 2006).

(3) Succar, Saleeb e Sher (2016) atribuem a cada série e uso do modelo BIM uma codificação, que remete aos conceitos adotados pelos autores e podem ser acessados via <http://www.bimexcellence.org/model-uses/>.

\section{Referências}

AKANMU, A. A..; ANUMBA, C. J.; MESSNER, J. I. An RTLS-based approach to cyber-physical systems integration in design and construction. International Journal of Distributed Sensor Networks, v. 8, n. 12, p. 596845, 2012.

doi:https://doi.org/10.1155\%2F2012\%2F596845

AKANMU, A. et al. Auto-generated site layout: an integrated approach to real-time sensing of temporary facilities in infrastructure projects. Structure and Infrastructure Engineering, v. 12, n. 10, p. 1243-1255, 2015.

doi:https://doi.org/10.1080/15732479.2015.1110601

ARSLAN, M. et al. Real-time environmental monitoring, visualization and notification system for construction H\&S management. ITcon, v. 19, p. 72-91, 2014. https://www.itcon.org/papers/2014_4.content.00814.pdf

ASHTON, K. That 'internet of things' thing. RFID Journal, v. 22, n. 7, p. 97-114, 2009.

https://www.rfidjournal.com/articles/view?4986

ASIN, A.; GASCON, D. 50 Sensor Applications for a Smarter World. Libelium Comunicaciones Distribuidas, Technical Report, 2012.

BIM DICTIONARY, BIM/IoT Interfacing. Disponível em: 〈https://bimdictionary.com/en/bimiot-interfacing/1/〉. Acesso em 08 de jul. 2017.

BOYES, H. Security, Privacy, and the Built Environment. IT Professional, v. 17, n. 3, p. 25-31, 2015.

COSTIN, A. M.; TEIZER, J.; SCHONER, B. RFID and BIM-enabled worker location tracking to support real-time building protocol and data visualization, ITcon, v. 20, p. 495-517, 2015. https://www.itcon.org/paper/2015/29

CROSBIE, T.; DAWOOD, N.; DEAN, J. Energy profiling in the life-cycle assessment of buildings. Management of Environmental Quality: An International Journal, v. 21, n. 1, p. 20-31, 2010. doi:https://doi.org/10.1108/14777831011010838

DAVE, B. et al. Opportunities for enhanced lean construction management using Internet of Things standards. Automation in Construction, v. 61, p. 86-97, 2016. doi:https://doi.org/10.1016/j.autcon.2015.10.009

DRESCH, A.; LACERDA, D. P.; ANTUNES JÚNIOR, J. A. V. Design Science Research: método de pesquisa para avanço da ciência e tecnologia. Ed. Bookman, 2015.

EASTMAN, C. Building Product Models: Computer Environments Supporting Design and Construction. Boca Raton: CRC Press, $1999,411 \mathrm{p}$.

EUROPEAN COMISSION. Vision and Challenges for Realising the Internet of Things. Luxembourg: Publications Office of the European Union. 2010. 229 p.

FANG, Y. et al. Case Study of BIM and Cloud-Enabled Real-Time RFID Indoor Localization for Construction Management Applications. Journal of Construction Engineering and Management, p. 05016003, 2016.

FENG, C. et al. An Intelligent Logistics Management Model in Prefabricated Construction. Frontiers of Engineering Management, v. 2, n. 2, p. 178-181, 2015. 
GAI, M; AZADMANESH, A.; REZAEIAN, A. A hybrid approach to indoor sensor area localization and coverage. Journal of Networks, v. 10, n. 4, p. 209-221, 2015.

GÖKÇE, H. U.; GÖKÇE, K. U. Holistic system architecture for energy efficient building operation. Sustainable Cities and Society, v. 6, p. 77-84, 2013. doi:https://doi.org/10.1016/j.scs.2012.07.003

GÖKÇE, H. U.; GÖKÇE, K. U. Integrated system platform for energy efficient building operations. Journal of Computing in Civil Engineering, v. 28, n. 6, p. 05014005, 2014a.

GÖKÇE, H. U.; GÖKÇE, K. U. Multi-dimensional energy monitoring, analysis and optimization system for energy efficient building operations. Sustainable Cities and Society, v. 10, p. 161-173, 2014b. doi:https://doi.org/10.1016/j.scs.2013.08.004

GUBBI, J. et al. Internet of Things (IoT): A vision, architectural elements, and future directions. Future Generation Computer Systems, v. 29, n. 7, p. 1645-1660, 2013. doi:https://doi.org/10.1016/j.future.2013.01.010

HABIBI, S. Smart innovation systems for indoor environmental quality (IEQ). Journal of Building Engineering, v. 8, p. 1-13, 2016. doi:https://doi.org/10.1016/j.jobe.2016.08.006

IKONEN, J. et al. Use of embedded RFID tags in concrete element supply chains. Journal of Information Technology in Construction (ITCon), v. 18, n. 7, p. 119-147, 2013. https://www.itcon.org/paper/2013/7

ISIKDAG, U. Enhanced Building Information Models. Springer, 2015.

KENSEK, K. M. Integration of Environmental Sensors with BIM: case studies using Arduino, Dynamo, and the Revit API 2014.

KENSEK, K. Visual programming for building information modeling: energy and shading analysis case studies. College Publishing, v. 10, n. 4, p. 28-43, 2015. doi:https://doi.org/10.3992/jgb.10.4.28

KITCHENHAM, B. Procedures for performing systematic reviews. Technical Report TR/SE-0401, Keele University and NICTA, 2004.

LEE, D.; CHA, G.; PARK, S. A study on data visualization of embedded sensors for building energy monitoring using BIM. International Journal of Precision Engineering and Manufacturing, v. 17, n. 6, p. 807-814, 2016.

LEE, S.; AKIN, O. Augmented reality-based computational fieldwork support for equipment operations and maintenance. Automation in Construction, v. 20, n. 4, p. 338-352, 2011. doi:https://doi.org/10.1016/j.autcon.2010.11.004

LEE, G. et al. A BIM-and sensor-based tower crane navigation system for blind lifts. Automation in Construction, v. 26, p. 1-10, 2012. doi:https://doi.org/10.1016/j.autcon.2012.05.002

LI, N.; BECERIK-GERBER, B.; SOIBELMAN, L. Iterative maximum likelihood estimation algorithm: leveraging building information and sensing infrastructure for localization during emergencies. Journal of Computing in Civil Engineering, v. 29, n. 6, p. 04014094, 2014.

LI, S.; DA XU, L.; ZHAO, S. The internet of things: a survey. Information Systems Frontiers, v. 17, n. 2, p. $243-259,2015$.

LI, N. et al. A BIM centered indoor localization algorithm to support building fire emergency response operations. Automation in Construction, v. 42, p. 78-89, 2014. doi:https://doi.org/10.1016/j.autcon.2014.02.019

LI, C. Z. et al. SWOT analysis and Internet of Things-enabled platform for prefabrication housing production in Hong Kong. Habitat International, v. 57, p. 74-87, 2016. doi:https://doi.org/10.1016/j.habitatint.2016.07.002

LI, C. Z. et al. Schedule risks in prefabrication housing production in Hong Kong: a social network analysis. Journal of Cleaner Production, 2016. doi:https://doi.org/10.1016/j.jclepro.2016.02.123

MARCH, S. T.; SMITH, G. F. Design and natural science research on information technology. Decision Support Systems, v. 15, n. 4, p. 251-266, 1995. doi:https://doi.org/10.1016/0167-9236(94)00041-2 
MARZOUK, M; ABDELATY, A. BIM-based framework for managing performance of subway stations. Automation in Construction, v. 41, p. 70-77, 2014a. doi:https://doi.org/10.1016/j.autcon.2014.02.004

MARZOUK, M; ABDELATY, A. Monitoring thermal comfort in subways using building information modeling. Energy and Buildings, v. 84, p. 252-257, 2014b. doi:https://doi.org/10.1016/j.enbuild.2014.08.006

MOTAMEDI, A. et al. Extending IFC to incorporate information of RFID tags attached to building elements. Advanced Engineering Informatics, v. 30, n. 1, p. 39-53, 2015. doi:https://doi.org/10.1016/j.aei.2015.11.004

MOTAMEDI, A. et al. Role-based access to facilities lifecycle information on RFID tags. Advanced Engineering Informatics, v. 25, n. 3, p. 559-568, 2011. doi:https://doi.org/10.1016/j.aei.2011.03.004

MOTAMEDI, A.; HAMMAD, A. Lifecycle management of facilities components using radio frequency identification and building information model. Journal of Information Technology in Construction (ITCon), v. 14, n. 18, p. 238-262, 2009. https://www.itcon.org/paper/2009/18

MOTAMEDI, A.; SOLTANI, M. M.; HAMMAD, A. Localization of RFID-equipped assets during the operation phase of facilities. Advanced Engineering Informatics, v. 27, n. 4, p. 566-579, 2013. doi:https://doi.org/10.1016/j.aei.2013.07.001

NBIMS. National BIM Standard Purpose. US National Institute of Building Sciences Facilities Information Council, BIM Committee, 2006. Disponível em: <http://www.nibs.org/BIM/NBIMS_Purpose.pdf> Acessado em: 01. jun. 2016.

NESS, D. et al. Smart steel: new paradigms for the reuse of steel enabled by digital tracking and modelling. Journal of Cleaner Production, v. 98, p. 292-303, 2015. doi:https://doi.org/10.1016/j.jclepro.2014.08.055

NIST - NATIONAL INSTITUTE OF STANDARDS AND TECHNOLOGY. NISTIR 7259: Capital Facilities Information Handover Guide, Part 1. Washington: U.S. Department of Commerce, 2006. 91 p.

NIU, Y. et al. Smart Construction Objects. Journal of Computing in Civil Engineering, p. 04015070, 2015.

OLBRICH, M. et al. Augmented reality supporting user-centric building information management. Visual Computer, v. 29, n. 10, p. 1093-1105, 2013.

OSELLO, A. et al. Energy saving in existing buildings by an intelligent use of interoperable ICTs. Energy efficiency, v. 6, n. 4, p. 707-723, 2013.

PARK, J.; KIM, K.; CHO, Y. K. Framework of Automated Construction-Safety Monitoring Using Cloud-Enabled BIM and BLE Mobile Tracking Sensors. Journal of Construction Engineering and Management, p. 05016019, 2016.

PENTTILÄ, H. Describing the Changes in Architectural Information Technology to Understand Design Complexity and Free-Form Architectural Expression. Journal of Information Technology in Construction, v. 11, special issue, p. 395-408, 2006.

https://www.itcon.org/paper/2006/29

PERERA, C. et al. Context aware computing for the internet of things: A survey. IEEE Communications Surveys \& Tutorials, v. 16, n. 1, p. 414-454, 2013. doi:https://doi.org/10.1109/SURV.2013.042313.00197

RIAZ, Z. et al. CoSMoS: A BIM and wireless sensor based integrated solution for worker safety in confined spaces. Automation in Construction, v. 45, p. 96-106, 2014. doi:https://doi.org/10.1016/j.autcon.2014.05.010

RIO, J.; FERRERA, B.; POCAS-MARTINS, J. Expansion of IFC model with structural sensors. Informes de la Construcción, v. 65, n. 530, p. 219-228, 2013.

RUEPPEL, U.; STUEBBE, K. M. BIM-based indoor-emergency-navigation-system for complex buildings. Tsinghua Science \& Technology, v. 13, p. 362-367, 2008. doi:https://doi.org/10.1016/S1007-0214(08)70175-5

SABOL, L. BIM Technology for FM. In: TEICHOLZ, P. (Ed.). BIM for Facility Managers. 1 ed. New York: John Wiley \& Sons Inc, 2013, P.17-45. 
SHADBOLT, N.; BERNERS-LEE, T.; HALL, W. The semantic web revisited. IEEE intelligent systems, v. 21, n. 3, p. 96-101, 2006. doi:https://doi.org/10.1109/MIS.2006.62

SUCCAR, B. Building information modelling framework: A research and delivery foundation for industry stakeholders. Automation in Construction, v. 18, n. 3, p. 357-375, 2009. doi:https://doi.org/10.1016/j.autcon.2008.10.003

SUCCAR, B.; SALEEB, N.; SHER, W. Model Uses: Foundations for Modular Requirements Clarification Language. In: AUSTRALASIAN UNIVERSITIES BUILDING EDUCATION (AUBEA2016), 2016. Proc... Cairns, Australia, 2016.

SUCCAR, B. The five components of BIM performance measurement. In: CIB WORLD CONGRESS, 2010. Proc... Salford, UK, 2010. doi:https://doi.org/10.1016/j.autcon.2008.10.003

SUH, S.; KIM, B.; CHUNG, J. H. Convergence research directions in cognitive sensor networks for elderly housing design. International Journal of Distributed Sensor Networks, v. 2015, p. 2, 2015. doi:https://doi.org/10.1155\%2F2015\%2F196280

TOMASI, R. et al. Leveraging BIM Interoperability for UWB-Based WSN Planning. IEEE Sensors Journal, v. 15, n. 10, p. 59885996, 2015. doi:https://doi.org/10.1109/JSEN.2015.2451736

UNDERWOOD, J.; ISIKDAG, U. Emerging technologies for BIM 2.0. Construction Innovation, v. 11, n. 3, p. $252-258,2011$. doi:https://doi.org/10.1108/14714171111148990

VALERO, E.; ADÁN, A.; BOSCHÉ, F. Semantic 3D reconstruction of furnished interiors using laser scanning and RFID technology. Journal of Computing in Civil Engineering, v. 30, n. 4, p. 04015053, 2015.

VERMESAN, O. et al. Internet of things strategic research roadmap. In: VERMESAN, O.; FRIESS, P. (Ed.). Internet of Things: Global Technological and Societal Trends. 1 ed. Aalborg: River Publishers, 2011, p.9-52.

XIE, H.; SHI, W.; ISSA, R. R. Using RFID and real-time virtual reality simulation for optimization in steel construction. Journal of Information Technology in Construction (ITcon), v. 16, n. 19, p. 291-308, 2011. https://www.itcon.org/paper/2011/19

WANG, X. et al. A conceptual framework for integrating building information modeling with augmented reality. Automation in Construction, v. 34, p. 37-44, 2013. doi:https://doi.org/10.1016/j.autcon.2012.10.012

ZHANG, Y.; BAI, L. Rapid structural condition assessment using radio frequency identification (RFID) based wireless strain sensor. Automation in Construction, v. 54, p. 1-11, 2015. doi:https://doi.org/10.1016/j.autcon.2015.02.013

\section{${ }^{1}$ Fernanda Almeida Machado}

Arquiteta e Urbanista. Mestre em Arquitetura, Tecnologia e Cidade pela Universidade Estadual de Campinas. Especialista em Gerenciamento BIM pelo SENAI CIMATEC. Diretora do Núcleo de Inovação BIM - NIB. Endereço postal: Rua Alceu Amoroso Lima, 668, Salvador, Bahia, Brasil, CEP: 41.820-770.

\section{${ }^{2}$ Regina Coeli Ruschel}

Engenheira Civil. Livre Docente em Projeto Auxiliado por Computador pela UNICAMP. Doutora em Engenharia Elétrica e da Computação pela UNICAMP. Mestre em Engenharia Civil pela University of Arkansa. Pesquisadora e Professora Colaboradora na Faculdade de Engenharia Civil, Arquitetura e Urbanismo (FEC) da Universidade Estadual de Campinas. Endereço postal: Av. Albert Einstein, 951, Campinas, SP, Brasil, CEP: 13.083-852. 